\title{
Permanentemente temporário: dekasseguis brasileiros no Japão
}

\author{
Kaizô Iwakami Beltrão* \\ Sonoe Sugahara*
}

\begin{abstract}
Este texto apresenta os resultados de parte de um projeto empreendido pela ABD (Associação Brasileira de Dekasseguis) sobre os dekasseguis, particularmente a partir dos dados do questionário aplicado a esses migrantes brasileiros no Japão, em janeiro de 2004. Uma grande barreira à adaptação dos dekasseguis no Japão está relacionada à língua e aos costumes. A maior parte, embora apresente um fenótipo de nativo japonês e possua ancestrais japoneses razoavelmente próximos, não se comporta mais como japonês. Esta aparente contradição entre o ser e o parecer gera conflitos de adaptação dos migrantes e de aceitação pelos nativos. Este conflito de identidade já existia no Brasil, mas a ida ao Japão só reforça o sentimento de não pertinência a este país e, conseqüentemente, reforça a identidade brasileira, expressa pela grande proporção de indivíduos que declaram "saudades do Brasil" como o problema que enfrenta no Japão. A pesquisa apontou que a motivação da ida ao Japão está ligada principalmente a questões econômicas, o que explica também a maior proporção de homens que viajam sozinhos e os reiterados retornos no caso de insucesso no Brasil, principalmente para o pessoal de mais baixa escolaridade. A situação dos dekasseguis com reiteradas idas e vindas no eixo Brasil-Japão, migrações internas freqüentes, bem como mudanças de emprego e passagens por períodos de desemprego no Japão (ainda que possivelmente curtos), tipificam o movimento dekassegui.
\end{abstract}

Palavras-chave: Dekassegui. Remessas internacionais. Migração laboral. Brasil. Japão.

\section{Introdução}

O termo dekassegui em japonês é formado por dois ideogramas (kanji), deru (出る-sair) e kassegu (稼ぐ - trabalhar para ganhar a vida), sendo aplicado a qualquer pessoa que deixa sua terra natal para trabalhar, temporariamente, em outra região. ${ }^{1}$ Originalmente, este termo era aplicado aos trabalhadores sazonais, principalmente do norte do Japão, que no inverno procuravam trabalho mais ao sul. Hoje, no Japão, este termo é aplicado aos trabalhadores estrangeiros temporários que estão naquele país com o intuito de ganhar dinheiro (exclui os expatriados - trabalhadores de firmas estrangeiras). No Brasil, a apropriação do termo ganhou contornos mais específicos, referindo-se aos brasileiros de origem nipônica e suas famílias

\footnotetext{
*Pesquisador do IBGE.

**Pesquisadora do IBGE.

${ }^{1}$ Ver Makoto Hoshi (1969).
} 
que emigram para o Japão em busca de trabalho - o chamado "fenômeno dekassegui". Este movimento começou no final da década de 80 e, oficialmente, teve início em junho de 1990, com a mudança na legislação de imigração japonesa, que concedeu aos descendentes de japoneses visto temporário de longa estadia (o que permite a atividade econômica no país). Constitui parte de um movimento migratório que se intensificou a partir dos anos 80 , com a crise econômica, e inclui outros destinos além do Japão - Estados Unidos (750 mil pessoas), Paraguai (350 mil) e Europa e outras regiões em geral $(705 \mathrm{mil})^{2}-$, rompendo a tendência histórica de um país que sempre foi um grande receptor de imigrantes de diferentes países.

O Brasil já havia recebido, entre o século XIX e começo do XX - portanto, antes de 1908, início da imigração japonesa -, cerca de 2 milhões de imigrantes italianos, além de portugueses e espanhóis. Neste período ocorreu uma maciça migração da Europa e parte da Ásia para as Américas. Estima-se que, até $1941,{ }^{3}$ período que Saito (1980) classifica como fase I, entraram quase 200 mil imigrantes japoneses e, entre 1953 e 1962, que o autor classifica como fase II, 50 mil. Os imigrantes da fase I caracterizavam-se por serem de procedência rural (pequenos proprietários ou proprietários arrendatários no Japão), direcionados aqui principalmente para a cultura do café e que vinham com a intenção de retorno após o sucesso econômico. Os imigrantes da fase II, muitos deles das antigas possessões e colônias japonesas (Taiwan, Coréia, Manchúria, etc.), chegaram com o intuito de relocação permanente e foram dispersos em núcleos coloniais (Amazônia, Nordeste, Sul, São Paulo e
Paraná). Com o aumento da industrialização no Japão e o "milagre brasileiro", a fase III trouxe um novo tipo de migrante caracterizado por capital-tecnologiaempresário, um contingente bem menos expressivo e com permanência limitada no país.

A partir do final da década de 80 , como já mencionado, o fluxo de migrantes mudou de direção. Esta reversão na tendência histórica intensificou-se com a crise econômica brasileira dos anos 80 e se tornou parte do movimento de globalização, com a incorporação de fluxos internacionais de mão-deobra aos crescentes fluxos de bens, serviços e capitais a nível mundial e, no caso do "fenômeno dekassegui", obviamente fruto da posição do Japão entre as potências industrializadas. Em princípio, couberam aos dekasseguis os trabalhos de baixa qualidade, rejeitados pelos japoneses e por eles denominados de " $3 K$ ": kitanai (sujo), kiken (perigoso) e kitsui (penoso). "Os brasileiros incluem ainda outras duas características [a este tipo de trabalho]: exigente [kibishii] e detestável [kirai]" (ROSSINI, 2004).

Sasaki (1998) classifica a migração dos dekasseguis brasileiros para o Japão em três períodos: pioneiro (meados da década de 80); massificação (final dos anos 80 e início dos 90); e consolidação das redes sociais (a partir de meados da década de 90). A nossa pesquisa se insere então no terceiro período de Sasaki.

Em 2000, segundo dados do Ministério da Justiça do Japão, aproximadamente 265 mil brasileiros ${ }^{4}$ viviam no Japão, remetendo anualmente entre US\$ 1,5 e US\$ 2 bilhões para o Brasil. ${ }^{5}$ Os brasileiros representam o terceiro maior contingente imigrante no Japão, atrás apenas dos chineses e dos

\footnotetext{
${ }^{2}$ Brasileiros no exterior (2005).

${ }^{3}$ Ainda que o tratado de amizade Brasil-Japão tivesse sido assinado em 1895 e as representações diplomáticas instaladas dois anos depois, foi somente em 1907 que a Cia. Imperial de Migração e a Secretaria de Agricultura de São Paulo assinaram o contrato para o envio de 3 mil migrantes no período de três anos. O Kasato Maru partiu do porto de Kobe, em 28 de abril, levando os primeiros imigrantes japoneses ao Brasil: 158 famílias num total de 781 pessoas. Este navio chegou ao porto de Santos em 18 de junho. ${ }^{4}$ Ministério da Justiça do Japão (2001). Os dados do Censo japonês de 2000 indicam um valor inferior a 190 mil. Possivelmente a diferença esteja relacionada tanto com dekasseguis retornados para o Brasil que mantêm a possibilidade do retorno em aberto (ou não) quanto com possíveis óbitos. Como os dados do Ministério da Justiça são baseados em registros administrativos (com base na Lei de Registros de Estrangeiros) e coletados nas prefeituras no final do ano, existe com certeza o problema da dupla contagem. Sasaki (1998) trabalha com dados do Ministério da Justiça e apresenta a mesma diferença.

${ }^{5}$ O BID (2005) estima que, em 2005, sejam enviados US\$2,2 bilhões para o Brasil pelos dekasseguis.
} 
coreanos. No Brasil, estes dekasseguis são contabilizados como o terceiro maior grupo vivendo fora do país. As remessas per capita dos dekasseguis são bem superiores às de outros migrantes laborais. Como o trabalho no Japão é relativamente bem pago e na prática não há limites para o número de horas trabalhadas, as remessas enviadas do Japão para a América Latina constituem, hoje, os maiores valores individuais deste tipo de fluxo monetário. Segundo pesquisa do BID, divulgada em Okinawa (abril de 2005), os dekasseguis enviaram, em média, US\$ 600 por mês para as suas famílias, ${ }^{6}$ valor bem superior aos US\$ 350 por ano enviados pelos imigrantes latinos dos EUA para seus parentes na América Latina.

Este texto apresenta os resultados de parte de um projeto empreendido pela $A B D$ (Associação Brasileira de Dekasseguis) sobre os dekasseguis brasileiros no Japão, particularmente a partir dos dados do questionário aplicado a esses migrantes brasileiros no Japão, em janeiro de 2004 (denominado questionário $\mathrm{B}$ ). $\mathrm{O}$ projeto incluiu também a aplicação de questionários a dois outros grupos: dekasseguis que haviam retornado ao Brasil (questionário $\mathrm{C}$ ); e potenciais dekasseguis, ou seja, brasileiros que tinham planos no curto prazo de irem trabalhar no Japão (questionário A), além de um levantamento documental. ${ }^{7}$ No Japão, os questionários foram aplicados a dekasseguis brasileiros que participaram das caravanas de saúde promovidas por voluntários ou que se dirigiram ao consulado do Brasil em Tóquio ou Nagoya durante o mês de janeiro, totalizando 321 indivíduos, sendo 176 homens e 145 mulheres.

Os dados dos censos japonês e brasileiro de 2000 servem para dar uma panorâmica do total da população que este estudo busca analisar. Apresenta-se, ainda, uma análise da população do questionário $B$, além dos comentários finais.

A distribuição por sexo, grupo etário e escolaridade para os brasileiros "amarelos" que declararam residência no Japão em
1995, no Censo 2000, serviu como base para uma pós-estratificação, em que se definiram as participações de cada indivíduo na amostra colhida no Japão. A amostra foi expandida para reproduzir a distribuição de sexo/idade/escolaridade com uma defasagem de dez anos. Utilizouse o pacote CSPRO para digitação dos dados dos questionários e tabulações. Os gráficos foram produzidos com o Excell.

\section{A população de brasileiros no Japão}

Os brasileiros que vivem no Japão constituíram, nos dois últimos censos (Tabela 1), o terceiro maior contingente de estrangeiros, quase equivalentes em número aos chineses. Ao contrário das principais populações asiáticas residentes no Japão (Coréia, China, Filipinas e Tailândia), entre os imigrantes brasileiros, os homens são em maior número do que as mulheres, o que de alguma forma reflete o tipo de trabalho e a distância ao país de origem (características compartilhadas com os peruanos). A maior diferença dos dekasseguis latino-americanos com outros segmentos de estrangeiros no Japão tem a ver com a origem: brasileiros e peruanos residentes no Japão são, usualmente, descendentes de japoneses (nikkeis 日系, literalmente de linhagem japonesa) ou casados com descendentes, condição necessária para o visto de longa permanência que permite a atividade laboral. A distribuição etária mostra que a população está concentrada nas idades economicamente ativas: $75 \%$ dos dekasseguis têm entre 20 e 59 anos (Gráfico 1).

Esta população de brasileiros encontrase, principalmente, na região central do Japão, como pode ser verificado na Tabela 2 , destacando-se as províncias vizinhas de Shizuoka e Aichi. A região de Aichi abriga um importante pólo industrial do Japão.

Quando se investiga a localização dos brasileiros que estavam no Japão em 2000 , cinco anos antes da data do censo

\footnotetext{
${ }^{6}$ Valores coincidentes com os levantados nesta pesquisa.

${ }^{7}$ Ver < www.abd.net.org.br > para descrição do projeto na íntegra.
} 
TABELA 1

Maiores contingentes de estrangeiros residentes no Japão, por sexo, segundo país de origem 1995-2000

\begin{tabular}{|c|c|c|c|c|c|c|}
\hline \multirow{2}{*}{ País de origem } & \multicolumn{3}{|c|}{1995} & \multicolumn{3}{|c|}{2000} \\
\hline & Total & Homens & Mulheres & Total & Homens & Mulheres \\
\hline Coréia & 560.414 & 271.529 & 288.885 & 529.408 & 249.045 & 280.363 \\
\hline China & 175.450 & 84.040 & 91.600 & 253.096 & 110.541 & 142.555 \\
\hline Brasil & 133.609 & 75.758 & 57.851 & 188.355 & 103.246 & 85.109 \\
\hline Filipinas & 68.496 & 14.049 & 54.447 & 93.662 & 16.555 & 77.107 \\
\hline EUA & 38.954 & 23.516 & 15.438 & 38.804 & 24.096 & 14.708 \\
\hline Peru & 27.112 & 15.661 & 11.451 & 33.608 & 18.295 & 15.313 \\
\hline Tailândia & 20.628 & 7.621 & 13.007 & 23.967 & 6.504 & 17.463 \\
\hline
\end{tabular}

Fonte: Japan Statistical Yearbook (2005).

\section{GRÁFICO 1}

Distribuição dos brasileiros residentes no Japão, por sexo e grupos de idade, segundo lugar de residência cinco anos antes Japão - 2000

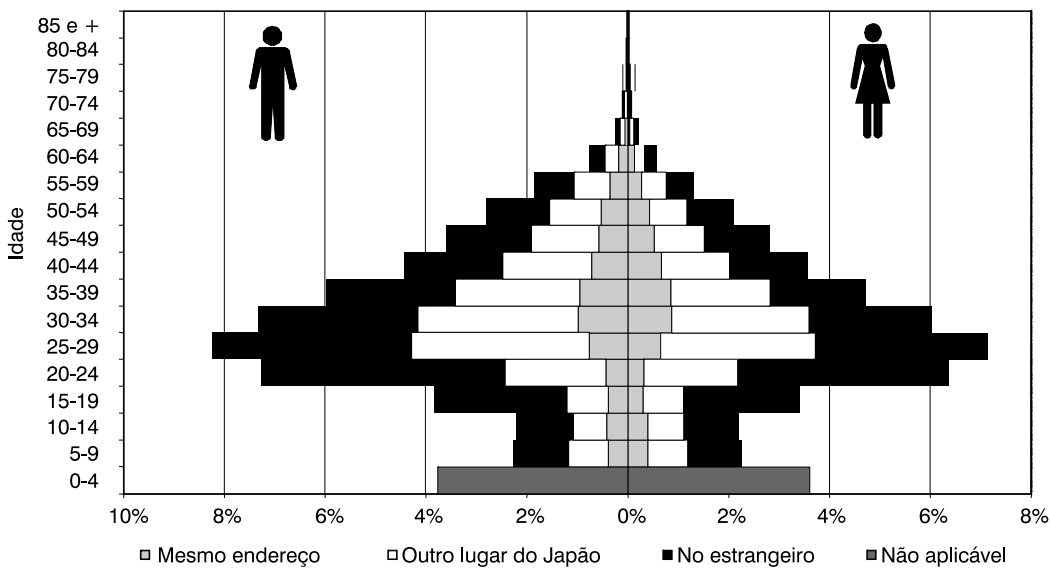

Fonte: Japan Statistical Yearbook (2005).

TABELA2

Distribuição dos brasileiros no Japão, por sexo, segundo província de residência 2000-2004

\begin{tabular}{|c|c|c|c|c|}
\hline \multirow{2}{*}{ Província } & \multicolumn{2}{|c|}{ Censo japonês (2000) } & \multicolumn{2}{|c|}{ Pesquisa de campo (2004) } \\
\hline & Homens & Mulheres & Homens & Mulheres \\
\hline Aichi & 18,9 & 19,1 & 15,9 & 5,6 \\
\hline Chiba & 2,3 & 2,6 & 6,2 & 3,6 \\
\hline Gifu & 5,7 & 5,6 & 3,3 & 2,1 \\
\hline Gumma & 6,1 & 6,3 & 5,4 & 11,6 \\
\hline Ibaraki & 4,2 & 3,7 & 4,5 & 2,2 \\
\hline Kanagawa & 4,7 & 4,9 & 16,3 & 20,3 \\
\hline Mie & 5,9 & 5,5 & 7,1 & 5,8 \\
\hline Nagano & 7,7 & 9,0 & 15,8 & 8,0 \\
\hline Osaka & 1,8 & 1,6 & 0,0 & 1,4 \\
\hline Saitama & 4,8 & 4,9 & 2,1 & 19,1 \\
\hline Shiga & 4,1 & 3,8 & 1,7 & 2,9 \\
\hline Shizuoka & 15,2 & 14,4 & 2,9 & 4,3 \\
\hline Tochigi & 3,3 & 3,5 & 3,8 & 2,8 \\
\hline Tokyo & 1,4 & 1,8 & 2,5 & 3,3 \\
\hline Toyama & 1,4 & 1,4 & 0,0 & 0,5 \\
\hline Yamagata & 0,2 & 0,2 & 0,8 & 0,8 \\
\hline Yamanashi & 1,8 & 1,7 & 0,8 & 2,1 \\
\hline Outros & 10,5 & 10,0 & - & - \\
\hline
\end{tabular}

Fonte: Japan Statistical Yearbook (2005); Associação Brasileira de Dekasseguis (2004). 
(migração de data fixa), percebe-se que a maioria não se encontrava no Japão e, portanto, sua permanência no país era inferior a cinco anos. Estes números indicam uma grande rotatividade entre os dekasseguis, já que o fluxo tem se mantido razoavelmente estável. Entre os que estavam no Japão há mais de cinco anos, observa-se também uma grande mobilidade: $13 \%$ dos homens e $14 \%$ das mulheres permaneceram no mesmo endereço; uma proporção um pouco maior (16,5\%) mudou de endereço na mesma cidade; cerca de $8,0 \%$ mudaram de cidade na mesma província; e $11,5 \%$ foram para outra província.

Quando se desagrega a informação sobre o local de residência ${ }^{8}$ cinco anos antes, por grupos etários, observa-se que o maior contingente dos que permaneceram no mesmo endereço corresponde à faixa etária de 30 a 40 anos, tanto entre os homens como entre as mulheres, quando se considera o total da população (Gráfico 1). Analisando-se por faixa etária, observa-se que o maior percentual daqueles que continuaram no mesmo endereço encontrase no grupo entre 60 e 69 anos para os homens e de 55 a 65 anos para as mulheres. O maior contingente dos que estavam há menos de cinco anos no Japão corresponde ao grupo etário entre 15 e 24 anos, para homens e mulheres.

O Censo japonês informa também a situação no mercado de trabalho e educacional para os contingentes estrangeiros. As possibilidades são: trabalhou; trabalhou fora e em afazeres domésticos; trabalhou e estudou; estava em férias ou em licença; desempregado; trabalhou em afazeres domésticos exclusivamente; estudou; e não trabalhou nem estudou. A maioria de homens e mulheres declarou ter apenas trabalhado. Entre as mulheres, a proporção das que afirmaram ter apenas realizado tarefas domésticas é maior do que as que declararam ter simultaneamente trabalhado e executado tarefas domésticas. Em todos os grupos etários, observa-se a presença

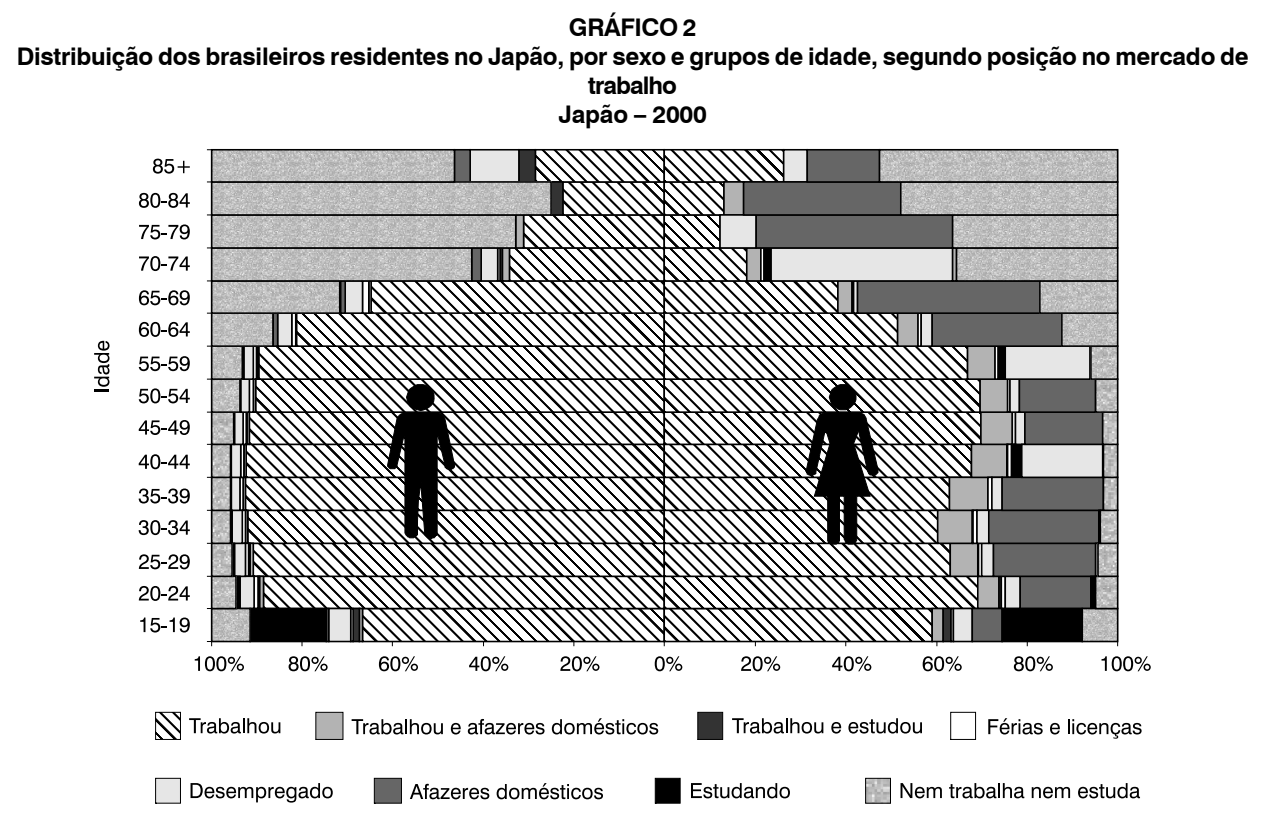

Fonte: Japan Statistical Yearbook (2005).

\footnotetext{
${ }^{8}$ Neste gráfico foram consideradas três categorias agregando-se as intermediárias dentro do Japão.
} 
de indivíduos que afirmaram não estudar nem trabalhar (Gráfico 2). É preocupante que, tendo sido a busca por trabalho a maior motivação para a ida ao Japão dos brasileiros, exista uma fração, ainda que residual, de desempregados.

As taxas de atividade (considerando as cinco primeiras categorias listadas pelo Censo japonês) apresentam a forma esperada: unimodal e com valores altos e razoavelmente constantes na faixa de 25 a 60 anos para os homens; e bimodal e com valores mais baixos para as mulheres. Vale a pena notar o valor discrepante para o grupo etário acima de 85 anos. Os estudantes se concentram particularmente nas idades inferiores a 20 anos, mas é estranho o fato de jovens terem declarado não estudar nem trabalhar. A mídia japonesa levanta freqüentemente o problema de delinqüência juvenil entre os brasileiros no Japão, o que muito provavelmente está ligado a estes indivíduos mais jovens que não trabalham e não conseguiram (ou não quiseram) se inserir no sistema educacional japonês. As escolas brasileiras no Japão são comparativamente mais caras, mas é a única saída para aqueles que chegaram ao Japão com idade superior à de alfabetização e sem o conhecimento do idioma falado/escrito japonês. Como várias das famílias de brasileiros consideram transitória a sua situação no Japão, não se esforçam para inserir os filhos no sistema escolar.

Ao se comparar o tipo de inserção no mercado de trabalho por ramo de atividade dos brasileiros residentes no Japão com os estrangeiros em geral, verifica-se uma grande concentração de brasileiros na produção $(90 \%$ dos homens brasileiros contra $50 \%$ do total de estrangeiros). A exceção entre os estrangeiros é a população de norte-americanos, que apresentam maior concentração em ocupação técnica e especial (tanto entre os homens quanto entre as mulheres). Os outros asiáticos, como os chineses e coreanos, estão representados em serviços e vendas mais fortemente do que os brasileiros e peruanos. Entre as mulheres Filipinas, a maior proporção está em serviços e, para as coreanas, em serviços e escritórios (Gráfico 3).

Quando se analisa a razão de sexo dos trabalhadores estrangeiros no Japão, observa-se grande presença masculina em

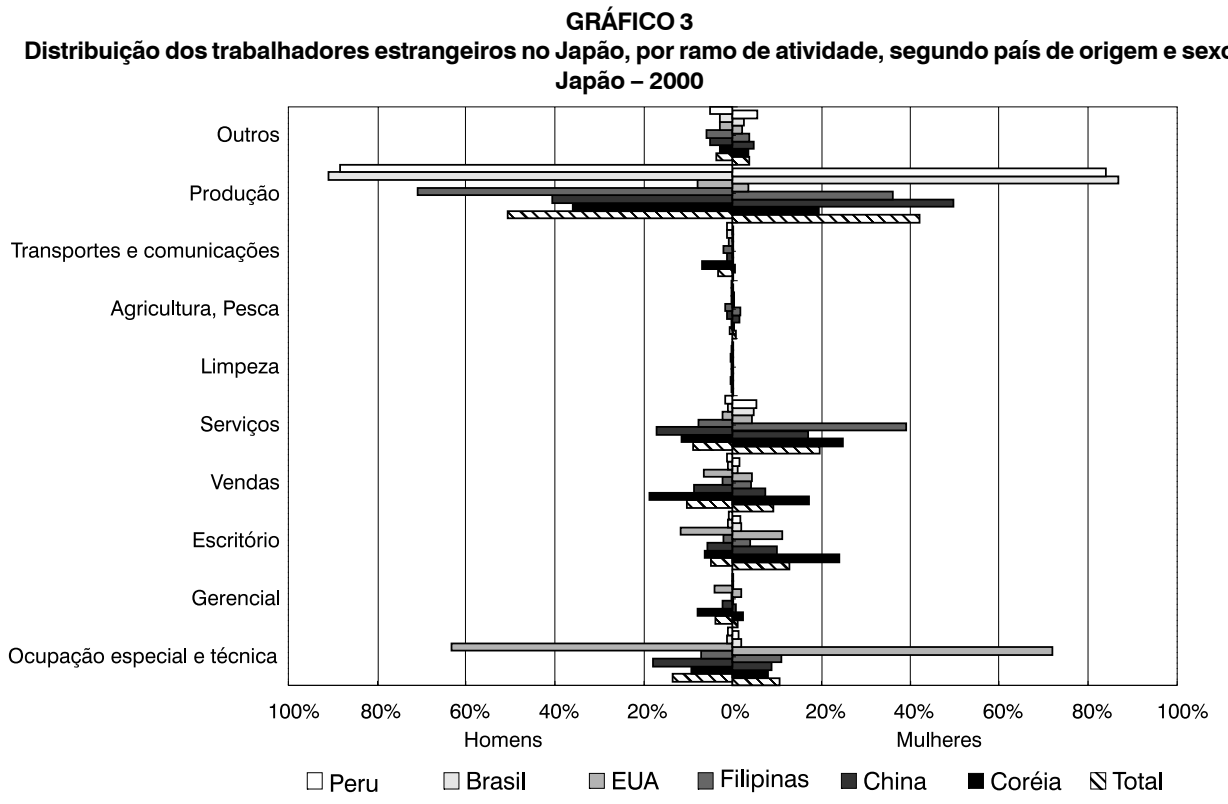

Fonte: Japan Statistical Yearbook (2005). 
transportes e comunicações, seguidos por serviços de limpeza, para todos os países. No caso dos norte-americanos, a maior presença de homens ocorre em todos os ramos de atividade listados no Gráfico 3. No caso dos brasileiros, a presença masculina só não é maior em serviços e escritório.

A maioria dos brasileiros vivia em domicílios formados por casal com filhos: 84.598 pessoas em 24.757 domicílios, perfazendo uma média de 3,4 membros por moradia. Era grande também o número de pessoas vivendo sozinhas (cerca de 40.000). Os domicílios com apenas o casal totalizavam 15.359. Havia 7.150 domicílios não-nucleares, com 24.390 moradores, e também 1.042 de não-parentes, com 2.147 indivíduos.

Considerando-se o tipo de moradia de estrangeiros no Japão, observa-se que a maioria das famílias brasileiras e de outras nacionalidades reside em domicílios alugados por particulares (Tabela 3). A proporção das famílias brasileiras que vivem em residência própria é irrisória, contrastando com a situação das outras estrangeiras. Cerca de $18 \%$ das famílias brasileiras residem em moradias alugadas pelo empregador, o que corresponde a uma proporção três vezes maior do que a encontrada para os estrangeiros em geral (7\%). As famílias brasileiras em moradias alugadas pelo governo local correspondiam a 8\% (com um tamanho médio de 3,22 membros) contra $7 \%$ dos estrangeiros em geral. As famílias brasileiras em domicílios alugados por empresas representavam cerca de $4 \%$, contra $3 \%$ para as estrangeiras. Os per- centuais correspondentes para famílias morando em quartos eram de, respectivamente, $7 \%$ e $5 \%$.

Considerando-se a área útil residencial por família de estrangeiros no Japão, segundo tipo de moradia, verifica-se que, entre os brasileiros, as famílias residentes em moradia própria desfrutam de maior área, seguidas por aquelas em domicílios alugados pelo governo local. Este padrão é semelhante entre as famílias dos demais estrangeiros.

\section{A população de descendentes de japoneses no Brasil}

No Censo brasileiro de 2000, cerca de 20 mil brasileiros, residentes em 31 de julho no Brasil, declararam ter estado no Japão cinco anos antes, isto é, em 1995. É evidente que não se pode supor que fossem todos dekasseguis retornados, mas, na ausência de informações mais específicas, utilizouse esse dado, bem como sua distribuição etária e de escolaridade, como guia para desenhar as quotas da pesquisa. A população que declarou ser o Japão a origem do último movimento migratório nos últimos dez anos é um pouco maior (Gráfico 4). Nota-se a semelhança no tocante à pouca presença de crianças e adolescentes, como na população de brasileiros no Japão (Gráfico 1).

Outra variável levantada e que se considerou de antemão ter um impacto no comportamento dos migrantes refere-se à escolaridade. O Gráfico 5 mostra a distribuição

TABELA 3

Distribuição das famílias imigrantes, tamanho médio e área média por família, segundo tipo de moradia Japão - 2000

\begin{tabular}{|c|c|c|c|c|c|c|}
\hline \multirow[t]{2}{*}{ Tipo de moradia } & \multicolumn{2}{|c|}{ Distribuição (\%) } & \multicolumn{2}{|c|}{$\begin{array}{l}\text { Tamanho médio da família } \\
\text { (membros) }\end{array}$} & \multicolumn{2}{|c|}{ Área média por família $\left(\mathrm{m}^{2}\right)$} \\
\hline & Estrangeiros & Brasileiros & Estrangeiros & Brasileiros & Estrangeiros & Brasileiros \\
\hline Própria & 25,3 & 0,6 & 3,44 & 3,14 & 111,9 & 92,30 \\
\hline Alugada pelo governo local & 7,3 & 7,5 & 3,00 & 3,22 & 50,6 & 51,20 \\
\hline Alugada por empresa & 2,8 & 4,2 & 2,74 & 2,73 & 49,7 & 44,20 \\
\hline Alugada por particular & 46,2 & 54,1 & 2,1 & 2,15 & 43 & 39,20 \\
\hline Alugada pelo empregador & 6,6 & 17,7 & & 1,85 & 48,9 & 35,70 \\
\hline Quartos & 4,8 & 6,7 & 1,4 & 1,15 & 24,2 & 19,00 \\
\hline Cohabitação & 7,1 & 9,3 & 1,13 & 1,20 & - & - \\
\hline
\end{tabular}

Fonte: Japan Statistical Yearbook (2005). 
GRÁFICO 4

População residente no Brasil cujo último movimento migratório teve como origem o Japão e aconteceu nos últimos dez anos, por sexo e grupos de idade

Brasil-2000

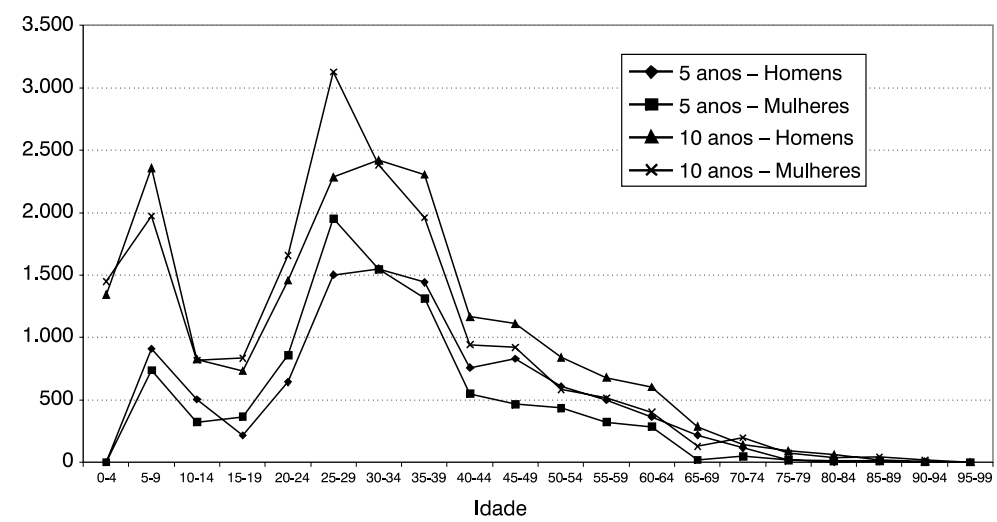

Fonte: IBGE (2003).

\section{GRÁFICO 5}

Distribuição da população residente que estava no Japão em 1995, por sexo e grupos de idade, segundo anos de estudo Brasil-2000

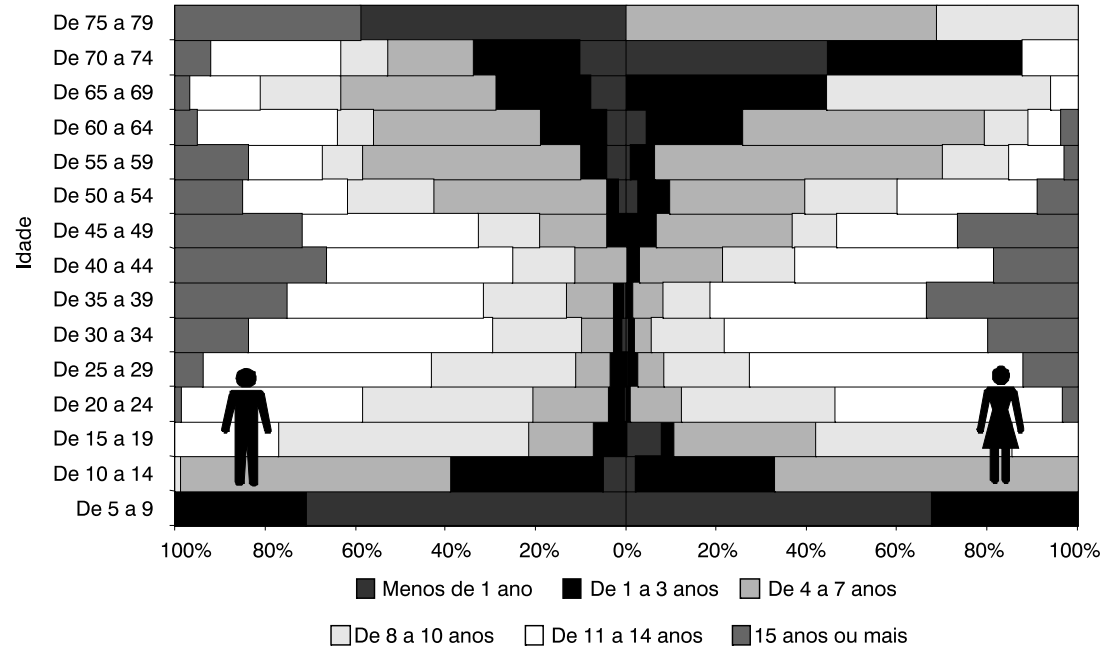

Fonte: IBGE (2003).

da população migrante ${ }^{9}$ por grupo etário, sexo e nível de ensino. Ao se comparar este gráfico com o Gráfico 6 , que mostra esta distribuição para o total da população amarela, notam-se diferenças marcantes: por um lado os migrantes possuem escola- ridade tipicamente menor para as idades mais jovens e, por outro, apresentam proporcionalmente menos indivíduos nos escalões educacionais mais baixos nos grupos etários em idade ativa e mesmo de idosos.

\footnotetext{
${ }^{9}$ Refere-se aos residentes no Brasil em 2000 que declararam estar residindo no Japão cinco anos antes com este termo, "migrantes".
} 


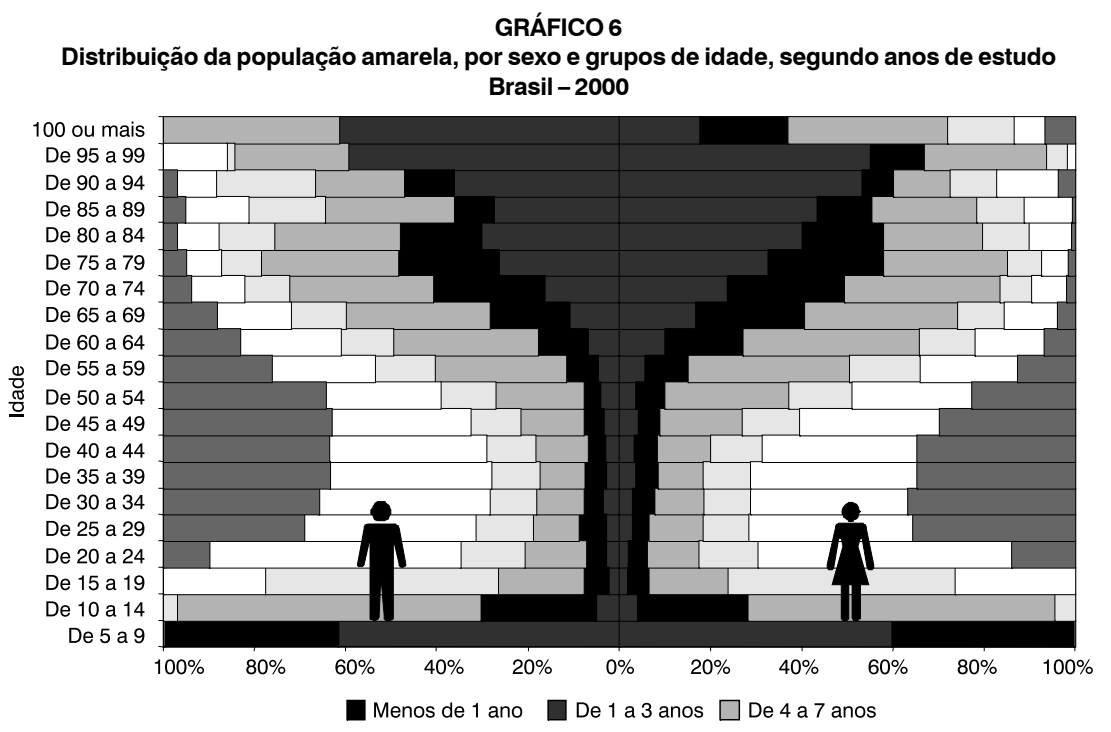

Fonte: IBGE (2003).

\section{Um breve perfil dos trabalhadores entrevistados}

Nesta seção serão analisados os dados obtidos a partir do questionário aplicado no Japão em janeiro de 2004, conforme mencionado na introdução, seguindo o mesmo procedimento adotado no questionário: características pessoais; a vida no Japão; e capacitação.

\section{Características pessoais}

Dado o caráter laboral da migração, a maior parte dos dekasseguis entrevistados concentra-se no grupo de idade entre 20 e 44 anos: $78,7 \%$ dos homens e $76,6 \%$ das mulheres. A faixa etária modal é a de 25 a 29 anos. Acima dos 55 anos de idade têmse apenas $5,8 \%$ dos homens e $6,7 \%$ das mulheres. Este perfil é consistente com o levantado pelo Censo japonês de 2000 (JAPAN..., 2005) e com levantamentos de populações similares, como o caso de migrantes internacionais de Maringá ${ }^{10}$ (FUSCO, HIRANO e PERES, 2002).
A maioria é casada $(67,5 \%$ dos homens e $63,1 \%$ das mulheres), ainda que nem todos tenham ido ao Japão com o seu cônjuge. O segundo maior contingente é formado pelos solteiros: $20,4 \%$ dos homens e $19,3 \%$ das mulheres. Em torno de $5 \%$ de ambos os sexos declaram que vivem junto (união consensual). Divorciados constituem $5,0 \%$ dos homens e $9,1 \%$ das mulheres e viúvos, respectivamente, $0,8 \%$ e $3,7 \%$.

A proporção de homens e de mulheres que foram acompanhados ao Japão - com esposo(a)/companheiro(a), com esposo(a) e filhos, com os pais, irmãos, amigos e outros - corresponde a, respectivamente, $55,9 \%$ e $78,8 \%$. Entre os homens, a moda é dos que viajaram sozinhos $(43,7 \%)$, enquanto para mulheres é das que foram com esposo/companheiro (24,3\%). Em linhas gerais, pode-se afirmar que as mulheres viajam em maior número com um suporte/ estrutura familiar, ao passo que os homens têm maior tendência à migração individual.

Entre os homens casados, $43,2 \%$ viajaram acompanhados de esposas e filhos e $38,2 \%$ foram sozinhos. Para as mulheres

\footnotetext{
${ }^{10}$ As populações não são comparáveis stricto sensu, pois esse artigo utiliza a informação dos migrantes levantada diretamente no Japão e o texto mencionado coleta a informação de famílias com migrantes, o que de saída elimina a possibilidade de incluir dados de famílias que migram na sua totalidade e que ainda se encontram no Japão.
} 
casadas, $63 \%$ viajaram acompanhadas de esposos e filhos e apenas $19 \%$ foram sozinhas. Entre solteiros, $61,3 \%$ dos homens viajaram sozinhos e $32,6 \%$ com os pais ou irmãos, enquanto para as mulheres esses valores correspondem a $22,6 \%$ e $77,4 \%$, respectivamente.

É interessante observar que, entre os homens, a proporção dos que viajaram acompanhados dos cônjuges e filhos é maior para aqueles cujo cônjuge é nikkei $(47,3 \%)$ do que entre aqueles com esposa não-nikkei (33,3\%). Já para as mulheres ocorre o contrário: das que viajaram acompanhadas dos cônjuges e filhos, $80,7 \%$ têm cônjuge não-nikkei, contra 58,4\% daquelas com cônjuge nikkei.

Quando considerada a escolaridade, verifica-se que a maioria tem ensino fundamental/médio. Juntos, constituem $82,9 \%$ dos homens e $83,8 \%$ das mulheres, valores semelhantes aos apontados por Fusco, Hirano e Peres (2002) para os dekasseguis de Maringá (83,5\%). Nesta população, não houve a ocorrência de pessoas com Mestrado/Doutorado. É importante notar que esta situação contrasta com a dos descendentes de japoneses no Brasil, que apresentam escolaridade bem mais alta do que a média populacional (Gráficos 5 e 6 . Para uma discussão comparando com outros grupos de cor/raça, ver Beltrão, 2005).

Em termos de descendência, a maioria é descendente de japoneses por parte de pai e mãe $(53 \%$ dos homens e $51 \%$ das mulheres) ou por parte de só um deles $(29 \%$ e $28 \%$, respectivamente, para os dois sexos). Os remanescentes, $18 \%$ dos homens e $21 \%$ das mulheres, são não descendentes de japoneses e seriam casados com descendentes, o que permitiria a ida ao Japão.

Quase todos têm descendência japonesa relativamente próxima. Entre os que apresentam descendência japonesa e responderam ao quesito, $52,8 \%$ dos homens e $51,1 \%$ das mulheres são japoneses ou têm pais japoneses; $45,1 \%$ dos homens e $47,9 \%$ das mulheres têm a geração mais próxima como sendo a dos avós. Esses números são, porém, inferiores aos encontrados para a população de dekasseguis já retornados ao Brasil (questionário $\mathrm{C}$ ), possivelmente por constituírem uma leva anterior e, em média, pelo menos dez anos mais velha. Nesta mesma linha, Sasaki (1998) descreve os dekasseguis da primeira leva nos anos 80 como: "das primeiras gerações (issei, nissei), (...) idade média avançada, (...) sabia falar japonês". Quando se considera o cônjuge, 66,9\% dos homens e $77,2 \%$ das mulheres possuíam cônjuge nikkei. Parece que existe entre os migrantes uma maior proporção de homens casados com não-nikkeis.

A atividade modal dos entrevistados do sexo masculino antes da ida ao Japão era a de operário (22,9\%), seguida pela de estudante de nível médio (17,5\%), balconista/comerciário $(10,8 \%)$ e profissional liberal $(10,8 \%)$. Entre as mulheres, cerca de $12 \%$ declararam ter sido donas de casa, $13 \%$ trabalharam em escritórios, mas a maior parte afirmou ter sido estudante de nível médio/fundamental (26\%). No Japão a esmagadora maioria trabalhava como operário, seja no chão de fábrica $(74,5 \%$ dos homens e $61,6 \%$ das mulheres), seja em outro tipo (respectivamente 9,6\% e 6,5\%). Entre as mulheres, quase $10 \%$ trabalhavam em indústria de comida, 6,6\% declararam ser donas de casa e $4,1 \%$ estavam desempregadas. Apenas 1,7\% dos homens afirmaram estar desempregados.

A Tabela 4 mostra o conhecimento da língua japonesa. A proporção daqueles com domínio do idioma japonês é relativamente pequena: apenas $20,8 \%$ dos homens e $14,4 \%$ das mulheres declararam falar bem o japonês. Porém, quando se inclui o grupo dos que afirmaram falar de forma regular, tem-se metade dos homens $(52 \%)$ e das mulheres $(50,9 \%)$. A proporção de pessoas que declararam entender bem o japonês é um pouco maior $(23,7 \%$ dos homens e $17,3 \%$ das mulheres). Se for considerado também o grupo daqueles com um entendimento regular da língua, chega-se a $58,7 \%$ dos homens e $57,0 \%$ das mulheres. Em termos de leitura, a proporção dos que declararam ler bem é bastante menor: $4,1 \%$ dos homens e $6,1 \%$ das mulheres. Mesmo incluindo aqueles que afirmaram ler de forma regular, tem-se um total de $21,2 \%$ dos 
TABELA 4

Distribuição dos dekasseguis brasileiros na amostra do Japão, por conhecimento da língua japonesa e sexo 2004

\begin{tabular}{|c|c|c|c|c|c|c|c|c|c|c|}
\hline \multirow{3}{*}{$\begin{array}{l}\text { Língua } \\
\text { japonesa }\end{array}$} & \multirow{2}{*}{\multicolumn{2}{|c|}{ Nada }} & & & & & & & Em pc & orcentagem \\
\hline & & & \multicolumn{2}{|c|}{ Pouco } & \multicolumn{2}{|c|}{ Regular } & \multicolumn{2}{|c|}{ Bem } & \multicolumn{2}{|c|}{ Não respondeu } \\
\hline & Homens & Mulheres & Homens & Mulheres & Homens & Mulheres & Homens & Mulheres & Homens & Mulheres \\
\hline Falar & 9,2 & 7,0 & 37,5 & 42,1 & 31,2 & 36,5 & 20,8 & 14,4 & 1,3 & 0,0 \\
\hline Entender & 5,0 & 2,8 & 35,5 & 39,5 & 35,0 & 39,7 & 23,7 & 17,3 & 0,8 & 0,7 \\
\hline Ler & 35,1 & 26,0 & 41,2 & 50,3 & 17,1 & 17,6 & 4,1 & 6,1 & 2,5 & 0,0 \\
\hline Escrever & 38,8 & 27,4 & 38,7 & 52,6 & 15,4 & 14,7 & 3,3 & 5,3 & 3,7 & 0,0 \\
\hline
\end{tabular}

Fonte: Associação Brasileira de Dekasseguis (2004).

\section{GRÁFICO 7}

Distribuição dos dekasseguis brasileiros na amostra do Japão, por condição de conhecimento da língua japonesa, segundo geração do respondente 2004

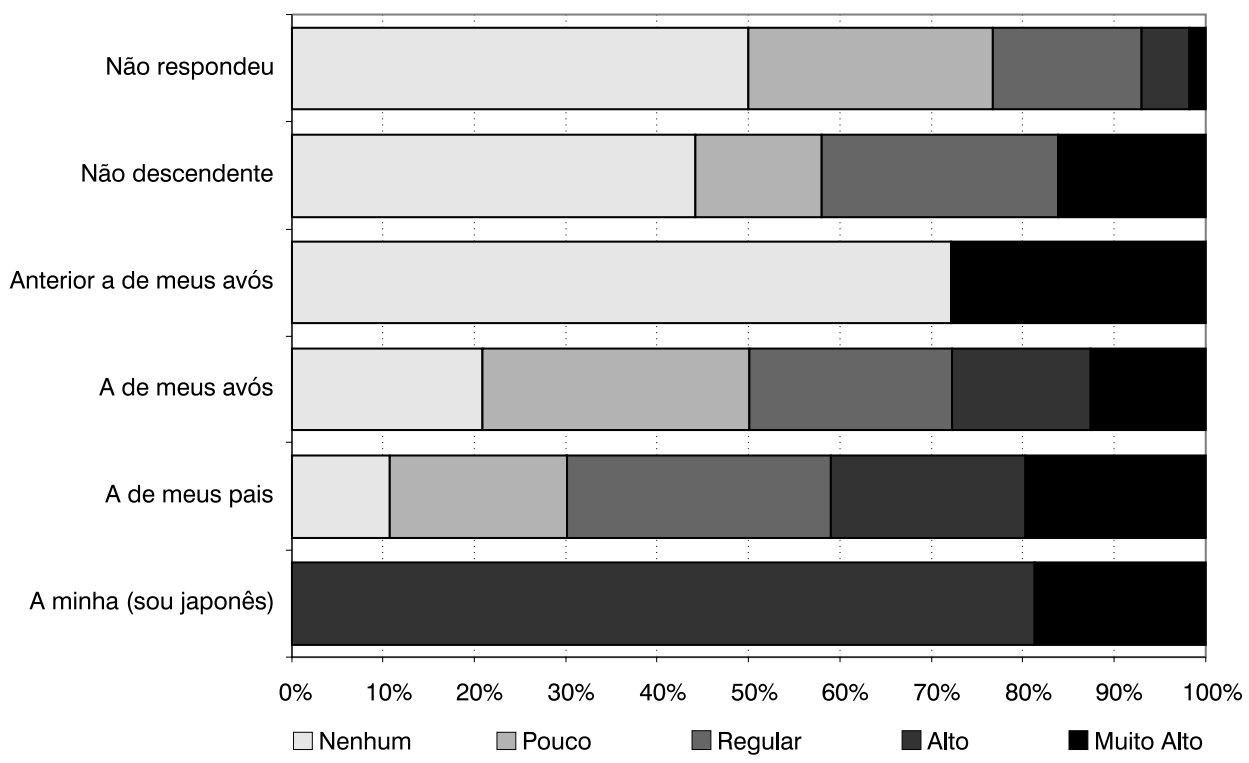

Fonte: Associação Brasileira de Dekasseguis (2004).

homens e $23,7 \%$ das mulheres. Obviamente a linguagem escrita é uma grande barreira para integração numa sociedade e deve impedir também a aquisição de capital cultural pelas vias usuais, ou seja, por meio de cursos específicos, manuais de instrução ou leitura de material didático japonês. Em termos de escrita, a proporção dos que declararam escrever bem é ainda menor: $3,3 \%$ dos homens e $5,3 \%$ das mulheres, que, somados àqueles que escrevem de forma regular, correspondem a apenas $18,7 \%$ dos homens e $20,0 \%$ das mulheres. Para estas informações sobre leitura e escrita, as mu-
Iheres apresentam situação ligeiramente melhor do que os homens.

Foi criada uma variável sintética ("conhecimento de japonês") para descrever os diferentes graus de conhecimento da linguagem falada, lida e escrita. Nesta variável foram definidas cinco categorias que combinam as informações referentes a falar, entender, ler e escrever: nenhum, pouco, regular, alto e muito alto conhecimento da língua japonesa.

Esperava-se que pessoas com maior escolaridade estivessem mais bem preparadas para lidar com a língua japonesa. $\mathrm{O}$ 
GRÁFICO 8

Distribuição dos dekasseguis brasileiros na amostra do Japão, por condição de conhecimento da língua japonesa, segundo nível de escolaridade

2004

Especialização/extensão

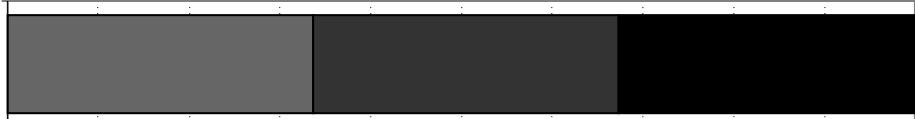

Ensino superio

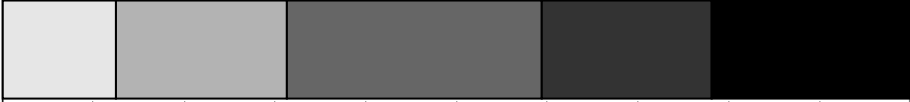

Ensino médio

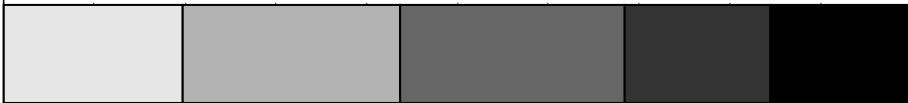

Ensino fundamental

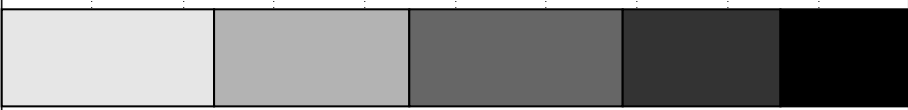

Sem instrução formal

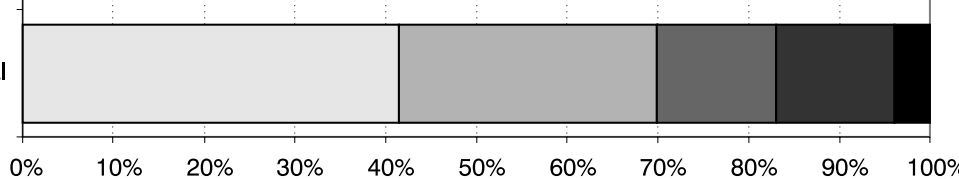

$\square$ Nenhum $\quad \square$ Pouco

$\square$ Regular

Alto

Muito Alto

Fonte: Associação Brasileira de Dekasseguis (2004).

mesmo deveria ocorrer para aquelas com ancestrais japoneses vindos do Japão num passado mais recente. Os Gráficos 7 e 8 confirmam estas asserções. Vale a pena notar que no gráfico por geração, as categorias "não respondeu" e "não descendente" apresentaram um nível de conhecimento da língua em média um pouco inferior ao dos dekasseguis de segunda geração (sanseis). Fusco, Hirano e Peres (2002) apontam para uma proporção de $30 \%$ de migrantes com níveis "excelente" ou "bom" de domínio do idioma do país de destino entre os migrantes de Maringá, comparável aos nossos níveis muito alto e alto, que agregam $31 \%$ dos migrantes.

\section{A vida no Japão}

Um pouco mais que a metade $(53,4 \%$ dos homens e $62,4 \%$ das mulheres) dos dekasseguis da amostra nunca tinham ido anteriormente ao Japão. A distribuição de número de idas anteriores (de uma a cinco) foi, respectivamente, de $13 \%, 19 \%, 6 \%, 2 \%$ e 2\% (Gráfico 9, na linha correspondente ao total). Parece que a migração para o Japão foi maior no passado entre os homens e agora está sendo realizada também por mulheres, conforme pode ser verificado por uma comparação com os dados dos dekasseguis retornados ao Brasil (ver dados do Questionário C, em Associação Brasileira de Dekasseguis, 2004).

Entre as mulheres, é bem marcada a diferenciação por escolaridade: aquelas com menor nível de estudo aparentemente retornam mais vezes ao Japão. Para os homens, aqueles sem instrução (menos de quatro anos de estudo) não se conformam a este padrão (Gráfico 9). É interessante notar que a quantidade de dekasseguis que já haviam ido outras duas vezes é superior aos que foram 1 ou 3 vezes. Considerando que o processo começou oficialmente no início da década de 90 , a existência de pessoas com até cinco estadias anteriores nestes 14 anos é sintomático: o processo se caracteriza por uma reincidência.

Uma permanência longa anterior no Japão não é muito freqüente: apenas $10 \%$ dos imigrantes permaneceram por mais de 


\section{GRÁFICO 9}

Distribuição acumulada do número de vezes que os dekasseguis brasileiros na amostra do Japão já foram ao Japão, por sexo e nível de escolaridade

2004
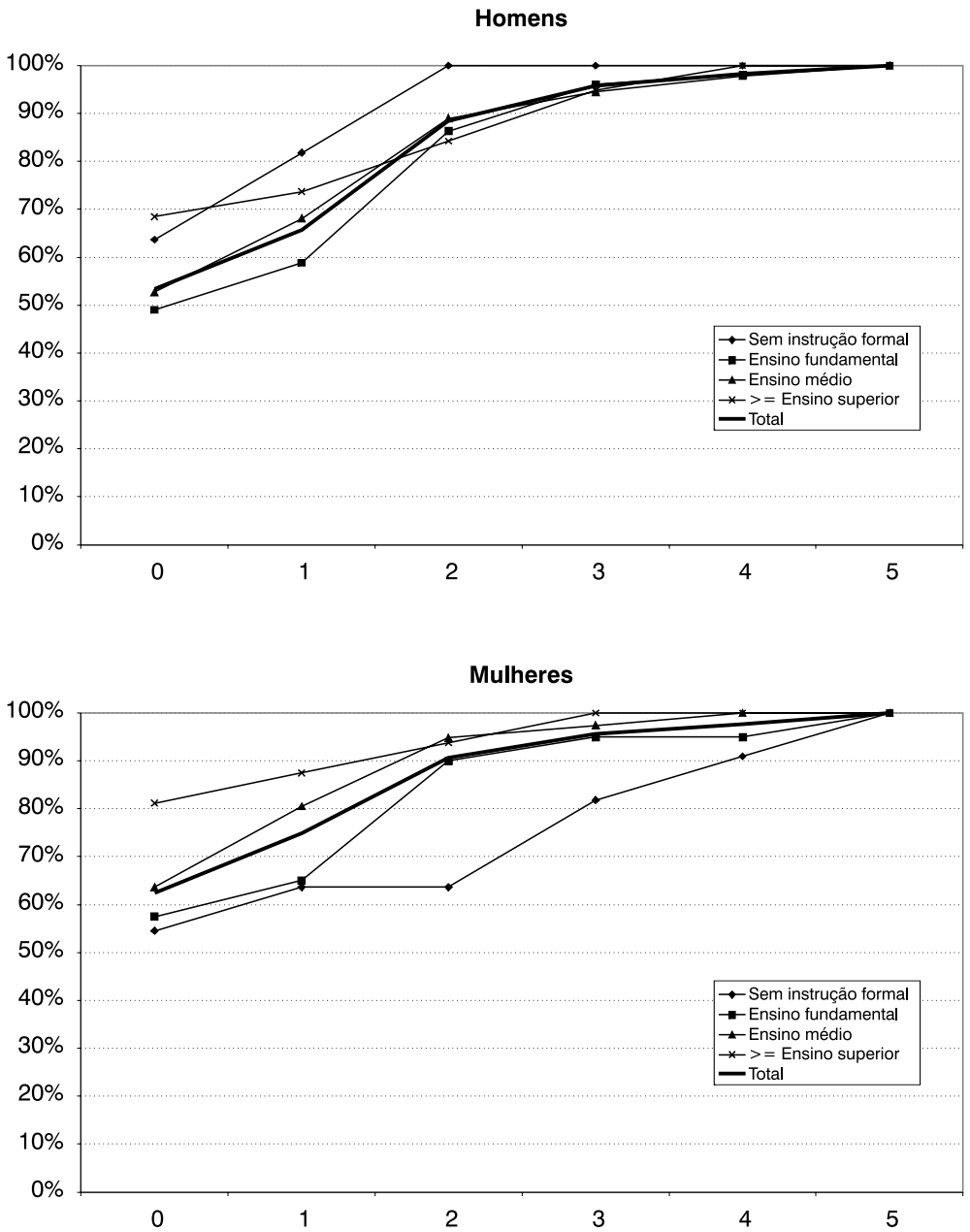

Fonte: Associação Brasileira de Dekasseguis (2004).

dez anos, como mostra a Tabela 5, sendo que a maioria (76\%) ficou até cinco anos. Entre os homens, $50 \%$ permaneceram menos de dois anos e $52 \%$ das mulheres, menos de um ano. Assim, como no caso das permanências anteriores, uma estadia atual longa no Japão não é muito freqüente, embora períodos maiores sejam mais usualmente observados do que no caso das estadias anteriores: $15,2 \%$ dos homens e $22,3 \%$ das mulheres permaneceram além de dez anos. Isto pode tanto indicar uma mudança temporal no comportamento (os novos migrantes ficam mais tempo) como uma não-uniformidade no comportamento dos dekasseguis com a dicotomia "mover/ stayer": alguns teriam mais idas e vindas entre Brasil e Japão com curtos períodos de permanência naquele país, enquanto outros, com menor probabilidade de migrar, ficariam por mais tempo. O período de permanência atual da maioria é de até cinco anos: $60,5 \%$ dos homens e $48,5 \%$ das mulheres. Aqueles que estão há menos de 
dois anos no Japão representam $19,8 \%$ dos homens e $14,4 \%$ das mulheres. Esta informação é consistente com os dados do Censo japonês sobre a migração recente dos estrangeiros no Japão.

Cerca da metade dos entrevistados não respondeu à pergunta sobre o motivo para retornarem ao Japão, devido, em parte, ao fato de terem ido somente uma vez. Entre os que responderam, as respostas mais citadas foram: poupar e insatisfação com a renda, para os homens, e desemprego, acompanhar a família e problemas no Brasil, para as mulheres. A segunda resposta apresentou situação financeira ruim no
Brasil como a opção mais freqüente, tanto entre os homens como entre as mulheres.

Um pouco mais da metade dos entrevistados não soube declarar quanto tempo pretendia ainda ficar no Japão, tanto entre os homens $(55,5 \%)$ como entre as mulheres $(53,5 \%)$. Esta informação indica o aspecto temporário desta migração, que prioriza uma meta econômica. O valor modal corresponde a mais de dois anos, para os homens, e menos de um ano, para as mulheres (Gráfico 10), porém, os valores são razoavelmente bem distribuídos entre as opções oferecidas. Aqueles que declararam pretender se radicar no Japão

TABELA 5

Distribuição dos dekasseguis brasileiros na amostra do Japão, por sexo, segundo tempo de permanência (anterior e atual) no Japão

2004

\begin{tabular}{cccccc}
\hline \multirow{2}{*}{ Anos de permanência } & \multicolumn{2}{c}{ Anterior } & & \multicolumn{2}{c}{ Atual } \\
\cline { 2 - 3 } \cline { 5 - 6 } & Homens & Mulheres & & Homens & Mulheres \\
\hline 0 & 43,0 & 52,0 & & 10,8 & 9,2 \\
2 & 10,3 & 4,8 & & 9,0 & 13,2 \\
3 & 3,1 & 7,0 & & 7,1 & 10,0 \\
4 & 5,8 & 0,8 & & 15,7 & 6,9 \\
5 & 6,7 & 6,2 & & 11,2 & 3,7 \\
6 & 3,6 & 5,6 & 6,7 & 6,3 \\
7 & 2,3 & 5,7 & & 6,3 & 7,7 \\
8 & 3,1 & 0,6 & & 6,3 & 7,1 \\
9 & 1,8 & 3,2 & & 5,4 & 7,0 \\
10 & 3,6 & 1,7 & & 1,4 & 2,3
\end{tabular}

Fonte: Associação Brasileira de Dekasseguis (2004).

\section{GRÁFICO 10}

Distribuição acumulada do tempo que os dekasseguis brasileiros na amostra do Japão pretendem ficar no Japão, entre os que declararam algum tempo, por sexo

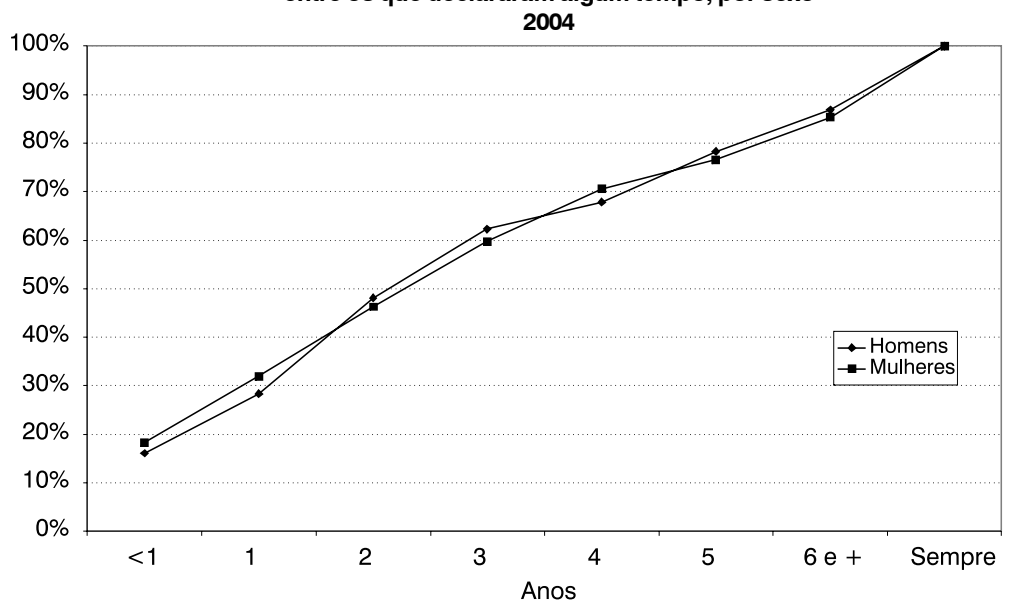

Fonte: Associação Brasileira de Dekasseguis (2004). 
representavam $5,8 \%$ dos homens e $6,8 \%$ das mulheres.

Quando se analisam as intenções, verifica-se que a maioria não pretende se fixar no Japão: $89,2 \%$ dos homens e $85,7 \%$ das mulheres. Esta situação é bem semelhante (e simétrica) à dos migrantes japoneses originais, da primeira leva (a fase I de Sato) quando da sua vinda para o Brasil: a maior parte considerava temporária sua estadia no Brasil e pretendia voltar ao Japão num futuro próximo.

A maioria tem intenção de regressar ao Brasil e abrir negócio próprio, tanto entre as mulheres como entre os homens (Tabela 6). Em segundo lugar nas escolhas (considerando-se múltiplas respostas) foi regressar ao Brasil com a poupança conseguida e viver de rendas/trabalho. A maior parte declarou não ter intenção de retornar ao Japão, mesmo que os negócios não dêem certo ou ocorram insucessos no Brasil.

Quanto à forma de obtenção de trabaIho, a alternativa mais assinalada foi aquela correspondente a agências de turismo/ agenciadoras/empreiteiras $(44,5 \%$ dos homens e $46,4 \%$ das mulheres), seguida por amigos/parentes $(41,7 \%$ e $46,2 \%)$, convite de empresa (8,4\% e $3 \%$ ) e jornais (2,5\% para ambos os sexos). Estes resultados são os mesmos encontrados para o pessoal que retornou (questionário $\mathrm{C}$ ) e para aquele que ainda pretende viajar (questionário A). Os dados relativos a agências foram substancialmente menores do que os $70 \%$ apontados por Fusco, Hirano e Peres (2002) para Maringá.

A proporção de pessoas que já estiveram ou se encontram desempregadas no Japão não é pequena: $28,2 \%$ dos homens e $30,7 \%$ das mulheres, além de ser preocupante, uma vez que foram para o Japão exatamente com o objetivo de trabalhar. Este valor é maior do que o declarado pelo pessoal que retornou (questionário $\mathrm{C}$ ), refletindo mudanças na economia japonesa. Entretanto, a proporção dos que declararam estar desempregados, segundo o Censo japonês, foi bem menor, como já mencionado: $2,8 \%$ entre os homens e $3,8 \%$ entre

TABELA 6

Dekasseguis brasileiros na amostra do Japão, por sexo, segundo declaração das intenções 2004

\begin{tabular}{lrc} 
& \multicolumn{2}{c}{ Em porcentagem } \\
\hline \multicolumn{1}{c}{ Intenções } & Homens & Mulheres \\
\hline Regressar ao Brasil e abrir negócio próprio & 63,0 & 43,8 \\
Regressar ao Brasil e contribuir com os negócios da família & 8,3 & 9,6 \\
Regressar ao Brasil com a poupança conseguida e viver de rendas/trabalho & 10,3 & 15,1 \\
Não regressar mais uma vez ao Japão mesmo que os negócios no Brasil não dêem certo & 3,8 & 5,4 \\
Voltar ao Japão se ocorrer insucesso no Brasil & 13,4 & 4,2 \\
Regressar ao Brasil, mas tem receio (da criminalidade, de não encontrar trabalho ou da & 8,7 & 7,6 \\
instabilidade econômica) & &
\end{tabular}

Fonte: Associação Brasileira de Dekasseguis (2004).

TABELA 7

Distribuição dos dekasseguis brasileiros na amostra do Japão, por sexo, segundo condição de Seguridade Social 2004

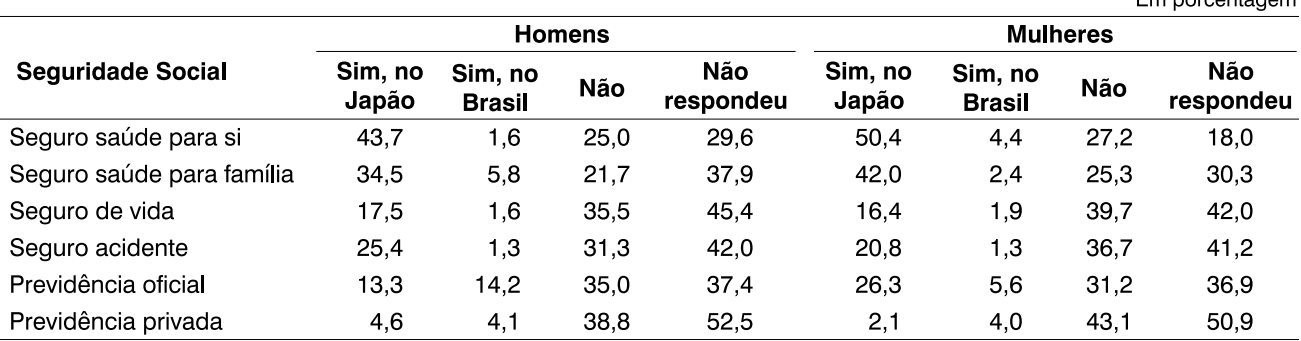

Fonte: Associação Brasileira de Dekasseguis (2004). 
as mulheres. Estes números apontam para uma rotatividade, característica da situação de precariedade nas relações de trabalho.

Com respeito à Seguridade Social, as coberturas de Previdência Oficial, Previdência Privada e Seguro de Acidentes não são muito abrangentes. Já as coberturas para saúde, tanto a nível individual como para a família, são mais freqüentes (Tabela 7 ). É impressionante que a proporção de trabaIhadores no Japão com cobertura previdenciária local seja tão pequena, reforçando mais uma vez a idéia da precariedade das relações de trabalho e a intenção de transitoriedade no país.

A maioria dos imigrantes mora em imóveis alugados por particulares $(57,8 \%)$, seguidos por aqueles que residem em domicílios alugados por empreiteiras (32\%). Imóveis próprios constituem percentuais semeIhantes (4,9\%) ao daqueles alugados por empresas (4,6\%). Estes números são bem similares aos apresentados pelo Censo japonês (o item "A população de brasileiros no Japão").

Quanto ao custo da passagem de ida para o Japão, $63,4 \%$ dos homens e $67,3 \%$ das mulheres, assinalaram a alternativa de custo "próprio/família". A opção de custeio por "empreiteiras/agenciadoras" foi predominante entre os que já retornaram do Japão (questionário C), que representam uma leva anterior. Este fato indica mudanças nas relações de trabalho. Entre os dekasseguis entrevistados no Japão, esta opção ocorreu para, respectivamente, $34,6 \%$ e $29,3 \%$ de homens e mulheres.

Quanto ao visto de entrada no Japão, a maioria possuía visto de permanência tem- porária (Tabela 8). Neste caso, entre o pessoal que já retornou do Japão (questionário $\mathrm{C}$ ), a predominância era de visto de turista, mostrando uma mudança na forma de entrada, sem subterfúgios. Na data da pesquisa, a maioria tinha visto de permanência temporária, mas em geral houve aumento da formalização, verificando-se, simultaneamente, crescimento da proporção de pessoas com permanência permanente e temporária e diminuição para aquelas com visto de turista.

Quanto ao objetivo da ida ao Japão, os entrevistados tinham acesso a uma lista de razões com a possibilidade de concordar ou discordar de cada uma delas (Tabela 9). Semelhante ao ocorrido entre os japoneses quando da sua migração para o Brasil, há quase 100 anos, poucos declararam a intenção de se fixarem na terra estrangeira: $1,7 \%$ dos homens e $4 \%$ das mulheres. As opções mais mencionadas sobre o motivo da ida ao Japão foram melhoria de vida e poupar para abrir negócios no Brasil. A razão econômica é apontada na literatura como a motivação primeira, mas a comparação não pode ser realizada pelo nível de desagregação adotado nesta pesquisa.

Poucos respondentes $(5,4 \%$ dos homens e 9,1\% das mulheres) não encontraram entre as opções oferecidas os objetivos da sua ida. Para os homens, a "curiosidade" e "pagar o estudo próprio e de filhos" foram os motivos (fora da lista disponibilizada) mais freqüentemente alegados (1,3\% para os dois). Cumpre notar que a primeira opção poderia ser encaixada na alternativa "conhecer o Japão" e, a segun$\mathrm{da}$, em "conseguir recursos para pagar os

TABELA 8

Distribuição dos dekasseguis brasileiros na amostra do Japão, por sexo, segundo tipo de visto na entrada e na data da entrevista

2004

Em porcentagem

\begin{tabular}{|c|c|c|c|c|}
\hline \multirow{2}{*}{ Tipo de visto } & \multicolumn{2}{|c|}{ Visto na entrada } & \multicolumn{2}{|c|}{ Visto na data da pesquisa } \\
\hline & Homens & Mulheres & Homens & Mulheres \\
\hline Turista & 39,3 & 38,7 & 0,0 & 0,7 \\
\hline Permanência temporária & 59,0 & 57,5 & 75,4 & 67,8 \\
\hline Permanência permanente & 0,4 & 1,5 & 16,2 & 23,8 \\
\hline Tem passaporte japonês & 1,3 & 0,0 & 3,8 & 0,7 \\
\hline Não respondeu & 0,0 & 2,3 & 4,6 & 7,1 \\
\hline
\end{tabular}

Fonte: Associação Brasileira de Dekasseguis (2004). 
TABELA 9

Dekasseguis brasileiros na amostra do Japão, por sexo, segundo objetivos para a ida ao Japão 2004

\begin{tabular}{lcc}
\hline \multicolumn{1}{c}{ Objetivos } & Homens & Mulheres \\
\hline Fugir do desemprego & 9,5 & 4,9 \\
Insatisfação com renda/salário & 17,4 & 15,9 \\
Busca de oportunidade de melhoria & 47,5 & 40,6 \\
Poupar dinheiro para investir no Japão & 1,7 & 0,7 \\
Acompanhar familiares & 11,3 & 28,8 \\
Poupar para abrir negócio no Brasil & 46,2 & 28,1 \\
Poupar para ajudar nos negócios da família & 7,5 & 5,9 \\
Acumular experiência numa área de trabalho & 12,1 & 5,7 \\
Sustentar a família & 20,9 & 16,0 \\
Conhecer o Japão & 17,5 & 15,1 \\
Fixar-se no Japão & 1,7 & 4,0 \\
Conseguir recursos para pagar os estudos & 6,6 & 15,0 \\
Conseguir recursos para pagar dívida & 6,6 & 15,0
\end{tabular}

Fonte Associação Brasileira de Dekasseguis (2004).

estudos". Entre as mulheres, comprar imóveis foi o grupo modal de longe, com $6,6 \%$ das respondentes, contra $0,4 \%$ para os homens. "Conseguir capital de giro" e "situação precária no Brasil" foram razões alegadas somente por homens. Para o contingente masculino aparece também $(0,4 \%)$ uma razão que poderia ser classificada de "atrativa" (por oposição às opções "expulsoras"): "gosta da infra-estrutura que o Japão oferece".

Um pouco menos de $2 / 3$ dos entrevistados declararam que seus objetivos estavam sendo alcançados, enquanto para cerca de $1 / 3$ isso ainda não havia acontecido. Uma minoria, entre as mulheres, não respondeu ou se mostrou altamente descrente quanto à possibilidade de alcançar os objetivos. A proporção dos que se mostraram desalentados com a situação foi ínfima e concentrada no segmento feminino.

Cerca de 2/3 dos dekasseguis declararam não ter filhos no Japão. Entre os que tinham filhos na escola, em torno de $22 \%$ afirmaram que os filhos tiveram problemas na escola.

A maioria declarou que a família se adaptou à vida no Japão ( $84 \%$ dos homens e $79 \%$ das mulheres). A proporção de pessoas que afirmaram categoricamente como não tendo se adaptado foi bem pequena e ligeiramente superior entre as mulheres ( $3 \%$ contra os $1 \%$ dos homens). Aqueles que declararam uma posição intermediária (mais ou menos) representavam $13 \%$ dos homens e $17 \%$ das mulheres.

Saudades do Brasil, desconhecimento da língua, discriminação e excesso de trabalho apareceram, nesta ordem, como as maiores dificuldades enfrentadas no Japão (Tabela 10). As três primeiras indicam uma não-adaptação ao novo país conjugada a uma nostalgia do antigo, o que aparentemente contradiz a declaração de adaptação das famílias à vida no Japão. A terceira dificuldade, em princípio, é autoimposta, pois com o objetivo de juntar dinheiro, o excesso de trabalho é uma necessidade. É interessante que a rebeldia dos filhos tenha apresentado uma proporção tão pequena de escolhas, dado que a mídia escrita e falada tem colocado este problema da delinqüência juvenil entre dekasseguis no Japão com muita ênfase. Este resultado é, porém, consistente com o fato de 2/3 dos entrevistados declararem não ter filhos no Japão.

Desagregando-se a informação das dificuldades enfrentadas seja por conhecimento da língua, seja por escolaridade, verifica-se uma não-uniformidade da situação, com maior incidência de problemas entre os grupos com menos escolaridade e/ou menor conhecimento da língua.

A maioria declarou que utiliza o telefone como forma de receber notícia de parentes e amigos do Brasil ( $77 \%$ de homens e mulheres). Cartas correspondem a cerca de 
TABELA 10

Dekasseguis brasileiros na amostra do Japão, por sexo, segundo dificuldades enfrentadas no Japão 2004

\begin{tabular}{lrr} 
& & Em porcentagem \\
\hline \multicolumn{1}{c}{ Dificuldades } & Homens & Mulheres \\
\hline Língua & 43,4 & 43,6 \\
Adaptação no emprego & 1,7 & 1,9 \\
Creche/escola para o filho & 3,3 & 5,5 \\
Doença/depressão & 3,7 & 10,6 \\
Saudades do Brasil & 49,2 & 49,4 \\
Rebeldia dos filhos & 0,8 & 3,2 \\
Adaptação aos usos, alimentação, costumes e pensamentos japoneses & 9,1 & 10,4 \\
Discriminação & 21,3 & 24,5 \\
Desemprego & 1,7 & 1,4 \\
Relação com autoridades & 1,7 & 0,5 \\
Relação com empregadores & 0,0 & 0,5 \\
Relação com colegas de trabalho japoneses & 5,0 & 5,6 \\
Relação com colegas de trabalho brasileiros & 8,7 & 9,7 \\
Relação com vizinhos & 2,1 & 0,8 \\
Relação com japoneses em geral & 4,6 & 3,0 \\
Excesso de trabalho & 12,5 & 20,6 \\
Aprendizado e manutenção da língua portuguesa com os filhos & 4,2 & 7,8 \\
Legislação local & 2,1 & 3,3 \\
\hline
\end{tabular}

Fonte: Associação Brasileira de Dekasseguis (2004).

$18 \%$ na primeira resposta. Os diferentes tipos de e-mails, principalmente o de casa, foram a resposta mais freqüente entre as segundas opções. Somente $0,5 \%$ declarou que não se comunica.

Cerca de metade dos entrevistados acompanha as notícias do Brasil através de rádio/TV $(51,7 \%$ dos homens e $44,1 \%$ das mulheres). Parentes e amigos são uma segunda fonte em importância, correspondente a um pouco mais de $1 / 4$ das entrevistas. A Internet aparece como terceira opção entre os homens (10,4\%), enquanto jornais e revistas surgem na mesma colocação entre as mulheres (8,3\%). Uma proporção maior de mulheres declarou não acompanhar notícias do Brasil $(7,1 \%$, contra 3,5\% para os homens).

A Tabela 11 apresenta a freqüência dos contatos, fora do trabalho, dos dekasseguis com diferentes grupos. Cerca de $30 \%$ a $40 \%$ dos entrevistados declararam ter contato diário com brasileiros fora do trabalho. No questionário $\mathrm{C}$ esta proporção foi de $2 / 3$, indicando uma comunidade mais endógena. Pelo menos $25 \%$ dos entrevistados afirmaram não ter contato nenhum com brasileiros fora do trabalho, o que mostra maior isolamento ou melhor adaptação desses migrantes. A rede de apoio, quando existe, não é composta de compatriotas. Mais da metade dos que responderam declarou que o contato com outros estrangeiros foi nenhum ou raro. A esmagadora maioria não parece ter contato com os parentes japoneses nativos, seja por ter perdido a comunicação antes mesmo da ida ao Japão, seja por distâncias internas do país, seja por não poder se expressar adequadamente em japonês, seja por vergonha da sua situação de trabalhadores 3K. Esta proporção é menor no questionário $\mathrm{C}$.

O contato com japoneses não-parentes é maior do que com aqueles que são parentes, cerca de $1 / 4$ das mulheres e $1 / 5$ de homens declaram contatos diários. Esta proporção é inferior àquela encontrada no questionário $\mathrm{C}$, mostrando maior distanciamento do dekasseguis em relação aos nativos. Uma grande maioria declarou não ter contato com colegas de atividades esportivas, principalmente por não praticálas. Esta proporção é substancialmente maior entre as mulheres. Uma forma de socialização fácil é através do esporte, e esse não parece ser um caminho trilhado pelos dekasseguis. Note-se que a proporção daqueles que afirmaram não ter nenhum contato entre os dekasseguis atuais é maior do que a observada para os respondentes do questionário $\mathrm{C}$. Da mesma forma, a religião não aparece como um canal de socialização da comunidade 
TABELA11

Distribuição dos dekasseguis brasileiros na amostra do Japão, por sexo e freqüência do contato no Japão, fora do trabalho, com os diferentes grupos

2004

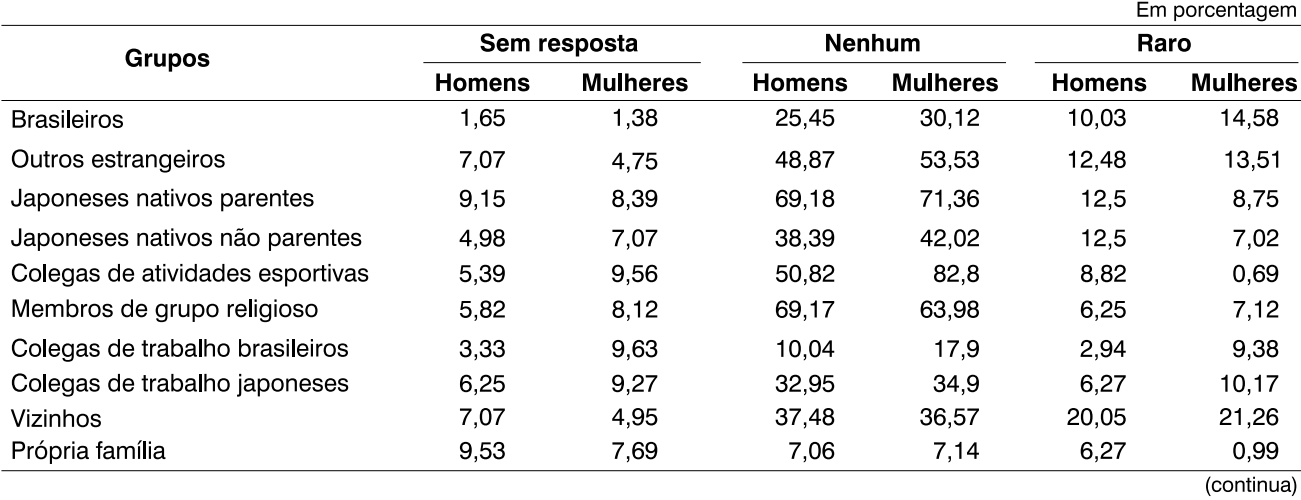

(continuação)

Em porcentagem

\begin{tabular}{|c|c|c|c|c|c|c|}
\hline \multirow{2}{*}{ Grupos } & \multicolumn{2}{|c|}{ Mensal } & \multicolumn{2}{|c|}{ Semanal } & \multicolumn{2}{|c|}{ Diário } \\
\hline & Homens & Mulheres & Homens & Mulheres & Homens & Mulheres \\
\hline Brasileiros & 4,56 & 6 & 19,56 & 12,79 & 38,75 & 35,12 \\
\hline Outros estrangeiros & 5,39 & 4,75 & 12,08 & 11,89 & 14,1 & 11,57 \\
\hline Japoneses nativos parentes & 1,26 & 2,75 & 3,72 & 3,57 & 4,19 & 5,18 \\
\hline Japoneses nativos não parentes & 7,54 & 9,01 & 14,55 & 8,49 & 22,05 & 26,39 \\
\hline Colegas de atividades esportivas & 10,43 & 1,94 & 20,37 & 4,26 & 4,17 & 0,76 \\
\hline Membros de grupo religioso & 4,56 & 8,25 & 12,13 & 11,77 & 2,07 & 0,76 \\
\hline Colegas de trabalho brasileiros & 4,98 & 5,94 & 12,47 & 11,02 & 66,24 & 46,13 \\
\hline Colegas de trabalho japoneses & 3,35 & 3,25 & 4,13 & 2,62 & 47,05 & 39,79 \\
\hline Vizinhos & 4,98 & 4,19 & 18,33 & 15,19 & 12,09 & 17,84 \\
\hline Própria família & 3,72 & 5,44 & 11,68 & 4,92 & 61,73 & 73,81 \\
\hline
\end{tabular}

Fonte: Associação Brasileira de Dekasseguis (2004).

dekassegui. Mais de metade declarou não ter nenhum contato com membro de grupos religiosos. Mais uma vez, a proporção de nenhum contato entre os dekasseguis atuais é superior à dos respondentes do questionário $\mathrm{C}$.

Parece que quase toda a socialização dos dekasseguis é feita através de relações no trabalho. Reforçando a idéia da endogenia laboral, a maioria declarou ter contato diário com os colegas de trabalho brasileiros (fora do trabalho). A grande socialização parece ocorrer por meio do trabalho e entre os próprios brasileiros e numa menor escala com colegas japoneses. Homens declararam maior contato com colegas de trabalho do que mulheres. É estranho que os contatos com vizinhos sejam tão esparsos e isso tanto entre os homens quanto para as mulheres, já que elas seriam as grandes socializadoras nos domicílios - mais de $57 \%$ não possuem, ou têm raramente, contato com os vizinhos

Considerando que nem todos os migrantes fizeram o movimento migratório com a família, a declaração de que mais de $60 \%$ têm contato diário com a família é reconfortante, implicando a existência de uma rede de suporte familiar. Tendo em vista que, para todos os outros contatos, a proporção da resposta "nenhum" é maior entre os dekasseguis no Japão do que entre os retornados (questionário $\mathrm{C}$ ), a impressão é de que os migrantes recentes estão mais fechados no grupo familiar.

A Tabela 12 apresenta a freqüência dos dekasseguis a diversos tipos de locais e eventos, o que retrataria parte da sua sociabilidade. Reforçando os quesitos de contatos com os diversos grupos, verifica- 
TABELA 12

Distribuição dos dekasseguis brasileiros na amostra do Japão, por sexo e condição de freqüência a locais no Japão 2004

\begin{tabular}{|c|c|c|c|c|c|c|}
\hline \multirow{2}{*}{ Locais } & \multicolumn{2}{|c|}{ Sim } & \multicolumn{2}{|c|}{ Não } & \multicolumn{2}{|c|}{ Sem resposta } \\
\hline & Homens & Mulheres & Homens & Mulheres & Homens & Mulheres \\
\hline Grupo religioso / igreja & 21,25 & 27,21 & 73,73 & 69,47 & 5,02 & 3,32 \\
\hline Associação esportiva & 20,42 & 5,32 & 74,13 & 91,18 & 5,45 & 3,5 \\
\hline Associação ligada ao trabalho & 1,64 & 0 & 91,25 & 95,31 & 7,11 & 4,69 \\
\hline Museus & 14,59 & 17,05 & 79,14 & 79,44 & 6,27 & 3,5 \\
\hline Teatro/cinema & 27,09 & 31,27 & 67,48 & 65,91 & 5,43 & 2,82 \\
\hline Curso profissionalizante & 5,81 & 4,99 & 87,92 & 89,64 & 6,27 & 5,37 \\
\hline Curso de japonês & 12,45 & 20,77 & 81,69 & 76,41 & 5,86 & 2,82 \\
\hline Feiras/seminários de negócios & 7,87 & 6,48 & 85,44 & 87,4 & 6,68 & 6,13 \\
\hline
\end{tabular}

Fonte: Associação Brasileira de Dekasseguis (2004).

se que a maioria dos entrevistados não freqüentou nem grupos religiosos, nem associações esportivas, nem associações ligadas ao trabalho. A impressão é de que o contato com os colegas de trabalho é totalmente informalizado, nunca canalizado através de alguma instituição.

Quanto à área de lazer/cultura, a indicação é que os dekasseguis pouco usufruem as oportunidades culturais oferecidas. É alarmante que mais de $3 / 4$ nunca tenham ido a um museu no Japão e mais de $2 / 3$ nunca foram a um teatro/cinema. É preocupante também que uma proporção ainda maior não teve nenhuma preocupação em aumentar o seu capital de conhecimento não freqüentaram curso de japonês (ainda que uma grande parte declare ser a língua um problema) e tampouco fizeram um curso profissionalizante.

Cerca de metade dos entrevistados ( $54,2 \%$ dos homens e $45,2 \%$ das mulheres) declarou que o treinamento recebido na empresa desenvolveu habilidades válidas no Brasil. ${ }^{11}$ Entre os que afirmaram ter aprendido algo, "métodos de trabalho" foi a resposta mais freqüente entre os homens $(30,1 \%)$, seguida de "organização, qualidade" $(13,7 \%)$. Entre as mulheres, a ordem destes dois quesitos é invertida, mas sendo ainda os dois mais importantes (respectivamente, $17,3 \%$ e 14,4\%). Algumas outras opções apareceram com freqüência acima de $1 \%$ : entre as mulheres, "escrita e fala" (3,8\%) e "área de alimentação" (3,5\%); e, para os homens, "cursos técnicos" $(3,0 \%)$. $\mathrm{O}$ questionário indagava sobre habilidades desenvolvidas e alguns entrevistados $(2,7 \%$ dos homens e 1,5\% das mulheres) assinalaram mais de uma resposta. Como segunda opção, "métodos de trabalho" foi a mais escolhida (respectivamente 1,8\% e 1,5\%).

Em princípio, homens trabalham mais horas do que mulheres. O período modal para ambos os sexos, coincidente com o mediano, é de 60 horas semanais trabalhadas, $50 \%$ a mais do que preconiza a legislação brasileira. As mulheres apresentam um outro máximo local para 48 horas semanais. A média é de 63,8 horas trabalhadas, entre os homens, e 57,3 , para as mulheres.

A maioria $(62,2 \%$ dos homens e $72,3 \%$ das mulheres) não declarou o objetivo financeiro a ser alcançado. Entre os que mencionaram, os dois valores com maior freqüência foram 50 e 100 mil dólares, para ambos os sexos.

Entretanto, 66,6\% dos homens e 58,3\% das mulheres afirmaram fazer remessas regulares para o Brasil, indicando possivelmente não a constituição de um patrimônio (que poderia ser feito no Japão), mas gastos correntes (neste quesito apenas $0,4 \%$ dos homens não responderam).

O valor médio dessas remessas é maior entre as mulheres: US $\$ 2.300,00$ contra US\$1.260,00 dos homens (ver Gráfico 11 com a distribuição das remessas declaradas, em escala logarítmica), mas o valor mediano é menor para as mulheres, que

\footnotetext{
${ }^{11}$ Esta pergunta foi respondida como um quesito aberto e as respostas obtidas foram agrupadas em 11 categorias.
} 
GRÁFICO 11

Distribuição acumulada das remessas enviadas ao Brasil pelos dekasseguis brasileiros na amostra do Japão, por sexo

2004

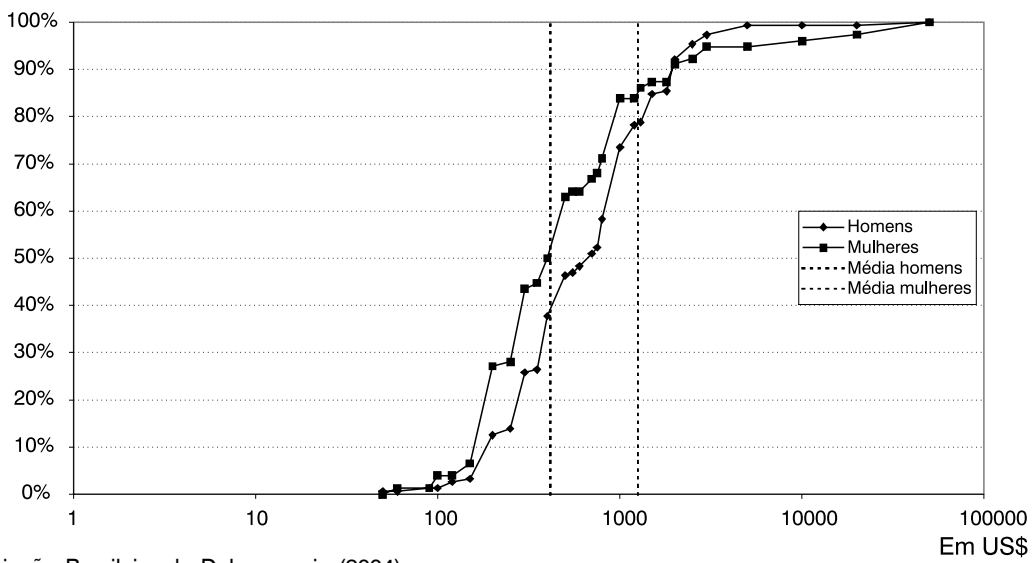

Fonte: Associação Brasileira de Dekasseguis (2004).

apresentam três valores discrepantes, provavelmente declarados em yens e não em dólares, resultando na elevação do valor médio das remessas femininas. Eliminando-se estes valores, o valor médio das remessas femininas diminui para US $\$ 630,00$. Os valores declarados foram principalmente múltiplos de 100 dólares, indicando arredondamento, seja na declaração, seja no envio propriamente dito. O valor modal correspondeu a US\$1.000. Entre os que fazem remessas regulares, a freqüência modal é a mensal $(73,8 \%$ dos homens e $66,3 \%$ das mulheres). Cerca de $8 \%$ declararam fazer remessas a cada dois meses e cerca de $20 \%$ a intervalos maiores. Uma menor proporção afirmou não ter regularidade nas remessas ( $2 \%$ dos homens e $1,3 \%$ das mulheres).

O valor médio mensal das remessas é de US\$ 820 para os homens e de US\$ 1.670 para as mulheres, reduzindo-se este último para US\$530 quando eliminados os valores discrepantes mencionados anteriormente.

\section{Capacitação}

Cerca de $52 \%$ dos entrevistados do sexo masculino e $80 \%$ do feminino não passaram por situação de chefia na sua atividade laboral no Brasil. Para os homens, as maiores dificuldades ocorreram nos quesitos planejamento e gerência, enquanto para as mulheres, em planejamento e execução.

A maioria dos entrevistados pretendia abrir o próprio negócio: $69 \%$ dos homens e $58 \%$ das mulheres. Uma proporção menor declarou estar em dúvida: respectivamente, $18 \%$ e $28 \%$. Os demais ou não responderam ou declararam que não tinham intenção de abrir negócio próprio. O preocupante é que entre os que pretendiam abrir negócio próprio, $65 \%$ declararam não ter tido nem experiência com chefia nem com negócio próprio. Entre os que estavam em dúvida, $73 \%$ encontravam-se na mesma situação.

A opção de cooperativismo/associativismo como forma de organização não foi considerada por $1 / 3$ dos entrevistados (mais precisamente $31 \%$ dos homens e $37 \%$ das mulheres), ainda que a maioria, como visto anteriormente, pensasse em abrir o próprio negócio. Os homens aparentavam ter a opção associação/cooperativa como mais desejável, já que $44 \%$ afirmaram que trabalhariam nesta modalidade, por oposição aos $32 \%$ das mulheres. Um não categórico foi expresso por $25 \%$ dos homens e $30 \%$ das mulheres.

A preocupação com as informações para o negócio e a situação da economia nacional parecia ser superior entre os 
homens, que também registraram maior nível de intenção em abrir negócios próprios. Quando indagados se eles "já tinham buscado informações no Japão ou no Brasil com pessoas que trabalham em negócios que deseja desenvolver no Brasil", um pouco mais da metade dos homens $(56,2 \%)$ e quase $3 / 4$ das mulheres (72,5\%) responderam que não (neste quesito apenas 2,9\% dos homens e $0,7 \%$ das mulheres não responderam). No que diz respeito ao acompanhamento da situação econômica e/ou de viabilidade dos negócios no Brasil (a pergunta formulada foi "Daqui do Japão você busca informações atualizadas sobre trabalho, empresas e economia do Brasil?"), também os homens pareciam mais preocupados ou pelo menos procuraram mais freqüentemente por informações (55\% contra $40 \%$ das mulheres) e, respectivamente, $19 \%$ e $32 \%$ afirmaram alguma procura.

O conhecimento da língua japonesa não afetou sobremaneira a busca por informações, mas a escolaridade sim: a proporção daqueles que responderam positivamente aos quesitos correspondentes à procura por informações sobre negócios ou trabalho/empresas/economia no Brasil é crescente com a escolaridade.

Um conjunto de questões tentou mensurar o interesse e a disponibilidade de tempo dos dekasseguis no Japão para freqüentar cursos não ligados diretamente ao trabalho. A maioria declarou ter interesse, mas não ter tempo como a razão para a não freqüência. Cerca de $1 / 3$ dos entrevistados não responderam as questões (com uma proporção maior quando se perguntou sobre a área da cultura). Uma pequena parcela declarou estar cursando, com percentuais maiores para cursos de língua japonesa (Tabela 13).

Ao se indagar sobre a necessidade de apoio quando do retorno ao Brasil, a maioria declarou precisar de algum tipo de apoio (89,6\% dos homens e $91,2 \%$ das mulheres). Menos de $10 \%$ afirmaram nunca ter pensado neste assunto $(10,4 \%$ dos homens e $8,8 \%$ das mulheres). A maior incidência ocorreu para cursos formativos para abertura de negócios, seguidos de adaptação ao país. Filhos parecem ser uma maior preocupação entre as mulheres: $25 \%$ declaram precisar de apoio contra os $11 \%$ dos respondentes masculinos. Documentação, assistência médica e ajuda psicológica tiveram em torno de $10 \%$ das respostas. Outros tipos de ajuda, não listados no questionário, tampouco foram muito mencionados (somente 2,1\% dos entrevistados). Além de duas opções, que seriam mais razões para não terem respondido o quesito ("não tem data prevista para voltar" e "morar em outro país"), as outras foram "aposentar", "em que aplicar" e "apoio do governo para agricultura", com menos de $1 \%$ cada uma.

A maioria dos entrevistados era proveniente de São Paulo, seguidos por aqueles do Paraná. Em terceiro lugar ficaram os de Mato Grosso do Sul e Rio de Janeiro.

O Estado de origem com maior dispersão na intenção de mudança foi São Paulo, também devido ao fato de ser o maior contingente. O Paraná apareceu como destino preferencial dos migrantes que não pretendiam retornar ao seu Estado de origem. A Bahia ficou com o segundo destino preferencial, seguida por São Paulo.

TABELA 13

Distribuição dos dekasseguis brasileiros na amostra do Japão, segundo disponibilidade de tempo/interesse em freqüentar cursos de língua, cultura, profissionalizante ou de gerenciamento 2004

\begin{tabular}{|c|c|c|c|c|c|c|c|c|}
\hline \multirow{2}{*}{ Disponibilidade } & \multicolumn{2}{|c|}{ Língua } & \multicolumn{2}{|c|}{ Cultura } & \multicolumn{2}{|c|}{ Profissionalizante } & \multicolumn{2}{|c|}{ Gerenciamento } \\
\hline & Homens & Mulheres & Homens & Mulheres & Homens & Mulheres & Homens & Mulheres \\
\hline Nem tempo nem interesse & 3,7 & 1,4 & 6,7 & 4,2 & 4,6 & 4,7 & 10,4 & 10,0 \\
\hline Tempo, mas não interesse & 3,8 & 2,4 & 5,9 & 4,6 & 2,9 & 3,2 & 5,0 & 2,4 \\
\hline Interesse, mas não tempo & 50,4 & 53,0 & 32,9 & 44,2 & 49,5 & 56,1 & 37,9 & 39,3 \\
\hline Gostaria, mas não sabe como & 7,5 & 8,8 & 5,8 & 8,4 & 11,7 & 10,5 & 7,9 & 8,7 \\
\hline Já freqüento & 5,4 & 10,1 & 0,0 & 2,1 & 1,7 & 1,2 & 0,0 & 0,0 \\
\hline Sem resposta & 29,2 & 24,3 & 48,7 & 36,6 & 29,6 & 24,3 & 38,8 & 39,6 \\
\hline
\end{tabular}

Fonte: Associação Brasileira de Dekasseguis (2004). 
A Tabela 2 apresenta a província declarada como residência pelos entrevistados. Segundo o Censo japonês, estas províncias concentram $90 \%$ da população brasileira no Japão. Cumpre observar que a amostra não foi desenhada para reproduzir a distribuição geográfica dos dekasseguis brasileiros no Japão, e a tabela serve para mostrar que o levantamento não se concentrou em poucas regiões, incluindo migrantes distribuídos na maioria das províncias com mais brasileiros.

\section{Comentários}

A população de dekasseguis apresenta escolaridade média inferior à dos descendentes de asiáticos no Brasil, porém mais alta do que a nacional. Cumpre notar que os nikkeis de escolaridade mais baixa e mais alta tampouco se tornam dekasseguis, os primeiros talvez por causa de barreiras de informação e os segundos pela existência de mais oportunidades.

Uma grande barreira à adaptação no Japão está relacionada à língua e aos costumes. A maior parte dos dekasseguis, ainda que apresente um fenótipo de nativo japonês e tenha ancestrais japoneses razoavelmente próximos, não se comporta mais como japoneses. Há um distanciamento nas relações com parentes japoneses: a maioria não estabelece contato com os parentes nativos, sendo maior o contato com japoneses não parentes. Por outro lado, alguns fatores, embora estreitamente ligados com o excesso de trabalho, indicam um desinteresse pela cultura japonesa: mais de $3 / 4$ dos dekasseguis entrevistados declararam nunca ter ido a um museu no Japão e mais de 2/3 afirmaram que nunca foram a um teatro/cinema. Uma proporção ainda maior declarou não freqüentar nenhum curso de japonês, mesmo mencionando ser a língua um problema.

Esta aparente contradição entre o ser e o parecer gera conflitos de adaptação dos migrantes e de aceitação por parte dos nativos. Este conflito de identidade já existia no Brasil, mas a ida ao Japão só reforça o sentimento de não pertinência a este país, e conseqüentemente, reforça a identidade brasileira, expressa pela grande proporção de pessoas que declararam "saudades do Brasil" como problema. Sasaki (1998) reforça esta idéia de não pertinência do nikkei brasileiro no Brasil e no Japão. Além desta, outras dificuldades enfrentadas foram citadas, tais como idioma e excesso de trabalho. Um outro fator que contribui para os conflitos de adaptação reside no tipo de atividade que exercem no Japão (completamente diferente dos tipos exercidos anteriormente no Brasil), normalmente atividades que exigem pouca especialização, a maioria como operários em fábricas e indústria em tarefas, como já mencionado, desprezadas pelos japoneses e sujeitos a longas jornadas de trabalho.

A pesquisa apontou como opções mais mencionadas para a ida ao Japão a busca por melhoria de vida e poupar para abrir negócios no Brasil. A motivação, portanto, está ligada principalmente a questões econômicas, o que explica também a maior proporção de homens que viajam sozinhos e os reiterados retornos no caso de insucesso no Brasil, principalmente para o pessoal de mais baixa escolaridade. A maioria destes dekasseguis declarou querer abrir negócio próprio. No entanto, eles não tinham nem experiência anterior nem haviam investido na aquisição de conhecimentos necessários. A situação desses migrantes com reiteradas idas e vindas no eixo Brasil-Japão, migrações internas freqüentes, bem como mudanças de emprego e passagens por períodos de desemprego no Japão (ainda que possivelmente curtos), tipificam o movimento dekassegui.

A maioria dos entrevistados $(89 \%$ dos homens e $86 \%$ das mulheres) declarou não pretender se fixar no Japão. É possível, porém, que, assim como seus antepassados que vieram para o Brasil com o firme propósito de retornar posteriormente e aqui ficaram, a situação simétrica possa vir a ocorrer com estes dekasseguis, acabando por construir uma vida permanente no Japão. Outra possibilidade seria a não resolução do conflito em nenhum dos dois países, tornando permanente e reiterado o movimento migratório. 


\section{Referências bibliográficas}

ASSOCIAÇÃO BRASILEIRA DE DEKASSEGUIS. Dekassegui: empreendedor e cidadão. Sebrae Nacional; [Curitiba]:, 2004. 73p. Kaizô Iwakami Beltrão; Sonoe Sugahara. Coordenadores da pesquisa de campo.

BELTRÃO, K. I. Raça e fronteiras sociais: lendo nas entrelinhas do centenário hiato de raças no Brasil. In: SOARES; BELTRÃO; FERRÃO; BARBOSA (Orgs.). Os mecanismos de discriminação nas escolas brasileiras. Rio de Janeiro: Ipea e Fundação Ford, 2005.

BRASILEIROS no exterior. Portal da Câmara dos Deputados. Seção: Relatórios, Artigos e Publicações. Disponível em: <http:// www2.camara.gov.br/comissoes/credn/ publicacao/NotatecnicaBrasileiros Exterior.html>. Acesso em: 12 nov. 2005.

FUSCO, W.; HIRANO, F. Y.; PERES, R. G. Brasileiros nos Estados Unidos e Japão. ENCONTRO NACIONAL DE ESTUDOS POPULACIONAIS, 13, Caxambu, 2002. Anais... Belo Horizonte: ABEP, 2002.

HOSHI, M. Novíssimo dicionário japonêsportugues. Cultural Japão-Brasil. Japão, 1969.

IBGE. Censo Demográfico - 2000. Rio de Janeiro: IBGE, 2003 (microdados, CDROM).

JAPAN Statistical Yearbook 2005. Statistical Bureau \& Statistical Research and Training
Institute. Ministry of Internal Affairs and Communications. The Portal Statistics Bureau of Japan. Disponível em: <http:// www.stat.go.jp/english/data/nenkan/ index.htm >. Acesso em: 12 nov. 2005.

KODAMA, K. O Sol nascente do Brasil: um balanço da imigração japonesa. Brasil: $\mathbf{5 0 0}$ anos de povoamento. Rio de Janeiro: IBGE, 2000, p.197-213.

ROSSINI, R. É. O Brasil no Japão: a conquista do espaço dos nikkeis do Brasil no Japão. ENCONTRO NACIONAL DE ESTUDOS POPULACIONAIS, 14, Caxambu, 2004. Anais... Belo Horizonte: ABEP, 2004.

SAITO (Org.). A presença japonesa no Brasil. São Paulo: T.A. Queiroz; Edusp, 1980.

SASAKI, E. M. Dekasseguis: migrantes brasileiros no Japão. ENCONTRO NACIONAL DE ESTUDOS POPULACIONAIS, 11, Caxambu, 1998. Anais... Belo Horizonte: ABEP, 2000.

SENDING, M. H. Remittances to Latin America and the Caribbean. Washington, D.C.: IADB, 2004. Study for the Multilateral Investment Fund, Inter-American Development Bank. Disponível em: <http://www.iadb.org/mif/v2/ files/StudyPE2004eng.pdf > . < http://idbdocs. iadb.org/wsdocs/getdocument.aspx? docnum $=547263>$. Acesso em: 12 nov. 2005.

\section{Abstract}

Permanently transient: Brazilian Dekasseguis in Japan

This article presents the results of part of a project undertaken by the Brazilian Association of Dekasseguis (ABD) regarding this group of Brazilians of Japanese descent who have migrated to Japan. The results are based mainly on answers given to a questionnaire applied in January 2004 to such Brazilian migrants in Japan. One great barrier to the adaptation of these immigrants in Japan is related to their language and customs. Although they have the native Japanese phenotype and reasonably recent Japanese ancestors, they no longer behave like Japanese. This apparent contradiction between being and seeming causes conflicts of adaptation for the migrants and their acceptance by the natives. This conflict of identity already existed in Brazil, but the move to Japan only reinforced their feeling of not belonging to this latter country. It 
consequently reinforces their Brazilian identity, expressed by the great majority of the individuals who said that the problem they face in Japan is that they "miss Brazil." The study indicated that most moved to Japan for economic reasons, a fact that explains the higher proportion of men who went alone and the repeated returns in cases of failure in Brazil, especially for those with lower educational levels. The situation of the Dekasseguis, with their constant coming and going between the two countries, frequent internal migrations, job changes and periods of unemployment in Japan (even though sometimes short) typify the Dekassegui movement.

Key words: Dekassegui. International fund transfers. Labor migration. Brazil. Japan.

Recebido para publicação em 30/01/2006.

Aceito para publicação em 17/03/2006. 